(C) 2014. This manuscript version is made available under the CC-BY-NC-ND 4.0 license

http://creativecommons.org/licenses/by-nc-nd/4.0/

\title{
COMPUTATIONAL AND EXPERIMENTAL STUDY OF A COMPLETE HEAT DISSIPATION SYSTEM USING WATER AS HEAT CARRIER PLACED ON A THERMOELECTRIC GENERATOR
}

\author{
Patricia Aranguren, David Astrain*, Miren Gurutze Pérez \\ Department of Mechanical Engineering. \\ Public University of Navarre, UPNa. Pamplona SPAIN. \\ *Tel: +34 948 169597, Fax: +34 948 169099, e-mail: david.astrain@unavarra.es
}

\begin{abstract}
The heat dissipation systems which have liquids as heat carriers outperform conventional dissipation systems at thermoelectric generators (TEGs). However, new elements need to be introduced such as pumps, secondary heat exchangers and piping.

A predictive computational model of a dissipation system involving refrigerant liquids has been implemented. The accuracy of the model is $93 \%$ for all its outputs: the total thermal resistance, the hydraulic losses and the auxiliary power consumption. The validation of the model has been done with a prototype mainly composed by a multi-channel heat exchanger, a fan-coil, a pump and several sensors: temperature, pressure and flow meters.

A study on the influence of the water and the air mass flow over the total thermal resistance has been conducted. The total resistance dependence on the air mass flow shows the importance of including the secondary heat exchanger into the thermal and hydraulic calculations. The smallest resistance does not always obtain the highest net power generation, the high demanding power of the auxiliary equipment needed to obtain this resistance influences negatively on the net power generation. Among the experimental points, the optimum scenario obtains a $40 \%$ additional power generation with respect to the smallest resistance point.
\end{abstract}

Key words: TEG, heat exchanger, optimization, multi-channels.

\section{Nomenclature}

A

$C_{p}$

$D$

$f$

g

$G r=\frac{g \beta\left(T_{s}-T_{\infty}\right) L^{3}}{v}$

$h$
Area

Specific heat

Pipe diameter

Friction losses coefficient

Gravity

Grashof number

Convective coefficient $\mathrm{m}^{2}$

$\mathrm{J} / \mathrm{kgK}$

m

$\mathrm{m} / \mathrm{s}^{2}$

$\mathrm{K} / \mathrm{m}^{2} \mathrm{~W}$ 


\begin{tabular}{|c|c|c|}
\hline$k$ & Thermal conductivity & $\mathrm{W} / \mathrm{mK}$ \\
\hline$k_{\text {local }}$ & Local losses coefficient & \\
\hline$L$ & Pipe length & $\mathrm{m}$ \\
\hline$\dot{m}$ & Mass flow & $\mathrm{kg} / \mathrm{s}$ \\
\hline $\mathrm{N}$ & Number of fins & \\
\hline$N u=\frac{h k}{D}$ & Nusselt number & \\
\hline $\operatorname{Pr}=\frac{C_{p} \mu}{k}$ & Prandtl number & \\
\hline$\dot{Q}$ & Heat power exchanged /transmitted & W \\
\hline$R$ & Thermal resistance & $\mathrm{K} / \mathrm{W}$ \\
\hline$R e=\frac{\rho v D}{\mu}$ & Reynolds number & \\
\hline$R a=G r P r$ & Rayleigh number & \\
\hline$T$ & Temperature & K \\
\hline$U$ & Global heat transfer coefficient & $\mathrm{K} / \mathrm{Wm} \mathrm{m}^{2}$ \\
\hline$v$ & Fluid velocity & $\mathrm{m} / \mathrm{s}$ \\
\hline$\dot{W}$ & Generated/consumed electric power & W \\
\hline \multicolumn{3}{|c|}{ Greek symbols } \\
\hline$\rho$ & Fluid density & $\mathrm{kg} / \mathrm{m}^{3}$ \\
\hline$\in$ & Material roughness & $\mathrm{m}$ \\
\hline$\eta$ & Efficiency & \\
\hline$\Delta P$ & Hydraulic losses & $\mathrm{kPa}$ \\
\hline$\Delta \mathrm{y}$ & Absolute measurement error & \\
\hline$\mu$ & Fluid dynamic viscosity & $\mathrm{kg} / \mathrm{ms}$ \\
\hline$v$ & Fluid kinematic viscosity & $\mathrm{m}^{2} / \mathrm{s}$ \\
\hline \multicolumn{3}{|l|}{ Subscripts } \\
\hline 1 & TEM-to-water heat exchanger entrance & \\
\hline 2 & TEM-to-water heat exchanger exit & \\
\hline 3 & Water-to-ambient heat exchanger entrar & \\
\hline
\end{tabular}


air

$a m b$

C

cond

cont

conv

$C P$

$e$

$\exp$

$f$

fin

$i$

net

$p$

sim

sys

TEM

tot

water
Air

Ambient

Thermoelectric module cold side

Conduction

Contact

Convection

Cold plate

Exterior

Experimental

Fan-coil

Fin

Interior

Net power generation

Pump

Computationally simulated

Piping assembly

Thermoelectric module

Total

Water

\section{INTRODUCCION}

Compactness, robustness, reliability and lack of moving parts are the main advantages of thermoelectric generators (TEGs). These features cause less maintenance and easiness of control, making TEGs a better solution than other energy conversion systems such as turbines or thermal engines. These benefits did not get unnoticed by the aerospace field; thermoelectricity has been present over 40 years at several spacecraft and satellites, with a special remark on Voyager probes capable of producing $150 \mathrm{~W}\left(\sim 350 \mathrm{~W} / \mathrm{cm}^{2}\right)$ with $7 \%$ efficiency [1]. The latest thermoelectric experience in the outer space is the vehicle space mission to Mars [2].

On the earth, several researches study the possible application of thermoelectricity in residual energy conversion. The origin of the waste energy can be very wide: vehicle exhaust gases, electricity generation or conventional industry chimneys. The $50 \%$ of the power consumption of automotive electronics can be generated 
recovering part of the waste energy being thrown to the atmosphere [3], a $10 \%$ fuel efficiency increase can be obtained locating TEGs on the exhaust tailpipe of vehicles [4].

Despite the costless nature of waste heat, the reduced efficiency that thermoelectricity presents is a decisive aspect over the applicability and profitability of big scale systems. Great efforts are being made to improve the overall efficiency of TEGs. Two are the main objectives: the optimization of materials, in order to improve the figure of merit, and the study of new heat exchangers towards the reduction of the thermal resistances on both sides of the thermoelectric modules (TEMs). The importance of reducing the thermal resistance between the heat source and the hot side of the TEM and its analogous in between the cold side and the ambient was demonstrated by Astrain et al. [5].

A high heat flux per area is what makes thermoelectricity special in terms of refrigeration. This issue occurs in other applications such as: electronics, laser diodes or microchemical reactors. One of the solutions focuses on heat exchangers provided with fluids as heat carriers (involving one or two phases). The dissipator can be composed by small channels or porous media [6]. For example, a thermosyphon loop cooling system obtains double refrigeration power than a traditional air convection system [7].

In terms of thermoelectricity, Zhou et al. [8] stated that liquid refrigerant heat exchangers generate higher net powers than conventional finned dissipators. Nevertheless, heat exchangers that include liquids need pumps to circulate the refrigerant. Each heat exchanger has a unique flow rate that obtains maximum net power generation [9]. At low mass flows, the pumping power can be negligible; however, the opposite occurs when the mass flow is considerable or the pressure drop is significant. Increasing 100 times the pressure drop (from 0.5 to $50 \mathrm{kPa}$ ) produces an increase of 3656 times of the pumping power in a specifically built heat dissipation system for a TEG [10].

The geometry optimization for the latter heat exchangers focuses on: number and geometry of the channels, flow distribution or the inclusion of inserts. The reduction of the diameter of the channels leads to heat transfer enhancement [11], parallel channels obtain higher net generation that serpentine ducts [12] and panel inserts can achieve a $50 \%$ net gain relative to the absence of inserts [13]. Latest researches present a $10 \%$ enhancement in power generation by introducing stirred flows into the heat exchangers [14]. They also propose the use of high thermal conductivity nanofluids as a feasible optimization field [11].

In the previous mentioned studies there is no treatment of the refrigerant; the costs of reusing the refrigerant are not included. Water can be used as refrigerant, but normally there are no big reservoirs near the generators where the water can be taken from.

In the present work each element involved in the refrigeration system has been taken into account. The dissipator located on the cold side, a secondary heat exchanger needed to reduce the temperature of the refrigerant, the pump and the piping itself. The computational model implemented in MATLAB computes the global thermal resistance, the hydraulic losses and the auxiliary equipment consumption. A specifically built 
prototype validates the model using 20 operating points that present different values of water and air mass flows. This global computational model is a powerful optimization tool for dissipation systems. Including its outputs in the TEG computational model presented in [5] the net generated power can be obtained.

The main objective of this study is to create and validate the tool which obtains the thermal resistance and the auxiliary power consumption. A study of the influence of water and air mass flows on the thermal resistances of the heat dissipation system has been included as well as a sample of the optimization potential that the methodology presented in this paper has.

\section{WATER-TO-AMBIENT HEAT DISSIPATION SYSTEM FOR A TEG SYSTEM}

A water-to-ambient heat dissipation system for a TEG dissipates the heat coming from the TEM to the heat sink. TEMs, due to the Seebeck effect, convert part of the heat received on their hot side into electric power. The rest of the heat is emitted through the cold side to the heat sink, normally the ambient.

In this work, the water is used as heat carrier due to its high convection coefficient. Nevertheless, the dissipation system which involves water is not as simple as in Figure 1; the water needs additional devices such as pumps, pipes and additional heat exchangers. Figure 2 shows every element of the dissipation system built.

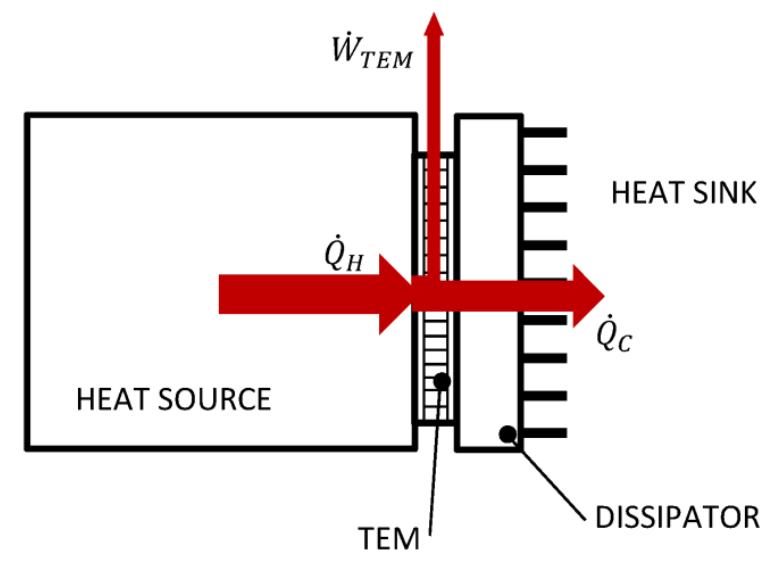

Figure 1: Schematic of the thermoelectric generator performance

Below the cold plate the TEMs are collocated. Their cold sides are in direct contact with the multi-channels heat exchanger, named cold plate. The cold plate of Figure 2 dissipates heat form the cold side of the TEMs as the dissipator of Figure 1 does. However, the dissipation system of Figure 2 is composed by two heat exchangers, a pump, pipes and valves among others. Normally TEGs are not close to rivers or water reservoirs, so the water needs to be cooled down via a secondary heat exchanger.

The behavior of TEG systems is simulated by Astrain et al. [5] through a computational model. The thermoelectric net power generation is the output of this model while the thermal resistances and geometries of the elements of the TEGs are the inputs. This model presents $95 \%$ accuracy. The computation of the total 
thermal resistance that the dissipation system of Figure 2 has and obtaining the auxiliary equipment consumption leads to obtain the thermoelectric net power generation. The optimization can be performed with the interaction of the two computational models presented above.

\section{COMPUTATIONAL MODEL}

The developed computational model solves the thermal resistances as well as the hydraulic losses of the dissipation system. A water mass flow range is simulated obtaining the dependence of the thermal resistances and hydraulic losses on the water flow. The total thermal resistance does not only depend on the water flow, but also on the air mass flow. The secondary heat exchanger, which is in charge of reducing the water temperature, has fans that help air to circulate over the fins. This fact is showing the importance of including each element of the dissipation system into the calculation of the total thermal resistance.

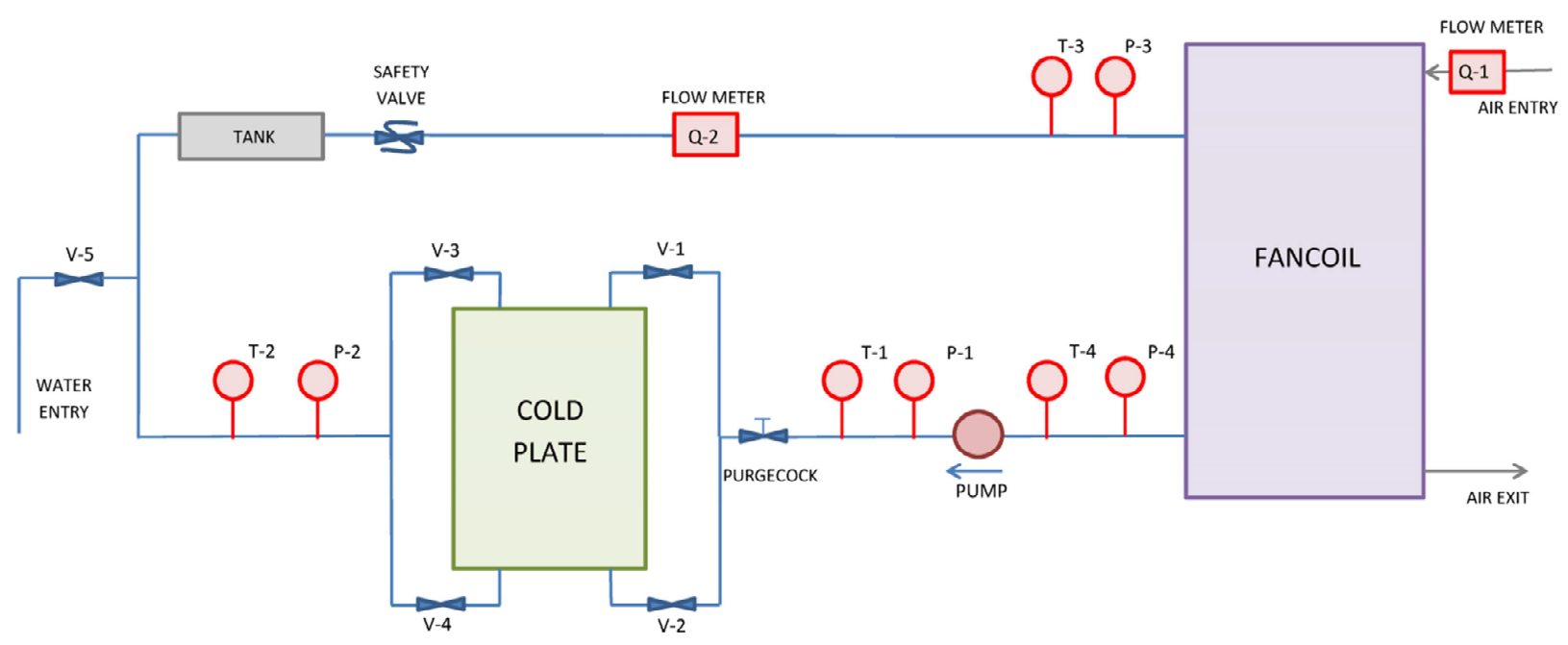

Figure 2: P\&I of the dissipation system

The computational model is composed by two stages, first, the temperature of the entries and exists of the two heat exchangers are obtained to secondly solve the hydraulic losses. The hydraulic losses are dependent on the temperature of the fluid; this is why the temperature is solved in a first instance.

The heat flux that the water is gaining at the cold plate is the starting point of the computational model. This heat exchanger is located on the cold side of a TEG, thus this heat flux is the heat that the TEMs are evacuating through their cold side. The heat gained by the water at the cold plate is the heat that the rest of the elements included in the dissipation system (fan-coil and pipes) need to dissipate in the steady state. A fixed water mass flow is used at each calculation.

$$
R_{t o t}=\frac{T_{C}-T_{a m b}}{\dot{Q}_{C}}
$$


Equation (1) obtains the total thermal resistance of the dissipation system, but $T_{C}$ is unknown. The thermal resistance of the cold plate is the term that connects $T_{C}$ with the temperatures of the key points of the system, Equation (2). Each temperature cannot be obtained separately, because it depends on the rest of them, so an equation system needs to be solved.

$$
\mathrm{R}_{\mathrm{CP}}=\frac{\frac{\left(\mathrm{T}_{\mathrm{C}}-\mathrm{T}_{1}\right)-\left(\mathrm{T}_{\mathrm{C}}-\mathrm{T}_{2}\right)}{\ln \left(\frac{\left(\mathrm{T}_{\mathrm{C}}-\mathrm{T}_{1}\right)}{\left(\mathrm{T}_{\mathrm{C}}-\mathrm{T}_{2}\right)}\right)}}{\dot{Q}_{C}}
$$

The temperatures are needed to calculate the thermal resistances of each element. This calculation is done by the global heat transfer coefficient presented in Equation (3).

$$
U_{e} A_{e}=\frac{1}{\frac{1}{A_{i} h_{i}}+\operatorname{cond}+\frac{1}{A_{e} h_{e}}}
$$

The three adding terms of the denominator correspond to the internal convective, the conduction and the external convective resistances. The thermal resistance of each component is obtained via the global heat transfer coefficient, Equation (3), but the cold plate. The internal convective coefficients are given by Equations (4)-(6). Laminar flows (Edwards) are represented by Equations (4) and (5) taking into account whether the flux is developed or not. Equation (6) dictates turbulent flows (Dittus Boelter) [15]. The fluid is being refrigerated, so that the Dittus Boelter term " $n$ " equals 0.3. The Prandtl numbers for water are all inside the range in which the equation is applied $(0.7<\operatorname{Pr}<160)$ and at each iteration the temperature difference between the surface and the liquid is checked to be less than $6^{\circ} \mathrm{C}$.

$$
\begin{gathered}
N u_{i}=3.66 ; \text { Developed region, } R e<10^{4} \\
N u_{i}=3.66+\frac{0.0668\left(\frac{D}{L}\right) R e_{D} \operatorname{Pr}}{1+0.04\left(\left(\frac{D}{L}\right) R e_{D} \operatorname{Pr}\right)^{2 / 3}} ; \text { Undeveloped region, } R e<10^{4} \\
N u_{i}=0.023 \operatorname{Re}_{D}^{0.8} \operatorname{Pr}^{0.3}, \operatorname{Re}>10^{4}
\end{gathered}
$$

Every fluid property is dependent on the temperature of the fluid.

The pipes have circular cross-sectional area, so that Equation (7) stands for the conduction resistance. The fan-coil is a circular pipe-continuous fin heat exchanger where water flows in both directions and it is cooled down by the air. The cross-sectional area of the pipes is also circular, thus Equation (7) is used.

$$
\operatorname{cond}=\frac{\ln \left(\frac{D_{e}}{D_{i}}\right)}{2 \pi k(T) L}
$$

To calculate the external convection two scenarios have been considered, natural convection (Churchill and Chu), Equation (8), and forced convection (Churchill and Bernstein), Equation (9). The velocity of the surrounding air is included into the computational model. 


$$
\begin{aligned}
& N u_{e}=\left.0.6+\frac{0.387 R a_{D}^{\frac{1}{6}}}{\left(1+\left(\frac{0.559}{\operatorname{Pr}}\right)^{\frac{9}{16}}\right)^{\frac{8}{27}}}\right)^{2} \text { Natural convection } \\
& N u_{e}=0.3+\frac{0.62 R e_{D}^{\frac{1}{2}} \operatorname{Pr}^{\frac{1}{3}}}{\left(1+\left(\frac{0.4}{\operatorname{Pr}}\right)^{\frac{2}{3}}\right)^{\frac{1}{4}}}\left(1+\left(\frac{R e_{D}}{28200}\right)^{\frac{5}{8}}\right)^{\frac{4}{5}} \text { Forced convection }
\end{aligned}
$$

As the fan-coil is a circular tube-continuous fin heat exchanger, the global heat transfer coefficient does not correspond with Equation (3). The fin efficiencies need to be included into Equation (3).

$$
\eta_{\text {tot }}=1-\frac{N A_{\text {fin }}}{A_{\text {tot }}}\left(1-\eta_{\text {fin }}\right)
$$

The calculation of the cold plate thermal resistance is more complicated. In Equation (2), the thermal resistance stands between the cold side temperature of the TEM and the temperature of the water. Three are the terms that compose the thermal resistance, the contact between the TEM and the cold plate, the conduction and the convection resistances.

$$
\begin{gathered}
R_{C P}=R_{\text {cont }}+R_{\text {cond }}+R_{\text {conv }} \\
R_{\text {cont }}=0.005 \mathrm{~K} / \mathrm{W} \\
R_{\text {cond }}=0.0011 \mathrm{~K} / \mathrm{W}
\end{gathered}
$$

The values of the contact and conduction thermal resistances of the cold plate (Equations (12) and (13)) correspond to the experimental values that the heat exchanger located on the cold side of the TEG has. The Nusselt conventional expressions are not valid to calculate the convective term. The mini geometry of the cold plate and its water mass flow, laminar along the entire flow range, create the necessity of modifying the conventional expressions. The Nusselt number correlations are not capable of predicting the heat transfer phenomena for laminar flows [16]. In this work an expression based on Sieder and Tate equation has been modified to obtain accurate results.

The heat fluxes that each element of the system dissipates are calculated through Equations (14)-(17).

$$
\begin{gathered}
\dot{Q}_{f}=\frac{U_{f} A_{f}\left(\left(T_{3}-T_{a m b}\right)-\left(T_{4}-T_{a m b}\right)\right)}{\ln \left(\frac{\left(T_{3}-T_{a m b}\right)}{\left(T_{4}-T_{a m b}\right)}\right)} \\
\dot{Q}_{23}=\frac{U_{23} A_{23}\left(\left(T_{2}-T_{a m b}\right)-\left(T_{3}-T_{a m b}\right)\right)}{\ln \left(\frac{\left(T_{2}-T_{a m b}\right)}{\left(T_{3}-T_{a m b}\right)}\right)} \\
\dot{Q}_{41}=\frac{U_{41} A_{41}\left(\left(T_{4}-T_{a m b}\right)-\left(T_{1}-T_{a m b}\right)\right)}{\ln \left(\frac{\left(T_{4}-T_{a m b}\right)}{\left(T_{1}-T_{a m b}\right)}\right)} \\
\dot{Q}_{s y s}=\dot{Q}_{23}+\dot{Q}_{41}
\end{gathered}
$$


The pipes are not isolated, so the heat dissipated through the piping $\left(\dot{Q}_{s y s}\right)$ is present.

An iterative process, starting with the supposition of $T_{1}, T_{3}$ and $T_{4}$ is proposed to achieve the temperature of the system. $T_{2}$ is obtained through Equation (18), the heat absorbed by the water at the cold plate $\left(\dot{Q}_{C}\right)$ is the input of the computational model.

$$
\Delta T_{12}=\frac{\dot{Q}_{c}}{C_{p} \dot{m}_{\text {water }}}
$$

Equation (18) associates the entry and exit temperature of the cold plate with the heat that the fluid is gaining. Equations (14)-(16) are used to build similar equations for each element. Thereby a linear system of three equations with three unknowns $\left(T_{1}, T_{3}\right.$ and $\left.T_{4}\right)$ emerges. The iteration process continues until each temperature difference between two consecutive iterations drops below a tolerance, in this case $10^{-6}$. At this point the hydraulic computation starts.

The total hydraulic losses are the sum of the losses of each element of the dissipation system.

$$
\Delta P_{t o t}=\Delta P_{C P}+\Delta P_{s y s}+\Delta P_{f}
$$

Each of the hydraulic loss is divided between the primary loses, $f L / D$, and the local ones $k_{\text {local }}$.

$$
\Delta P=\frac{v^{2}}{2}\left(\frac{f L}{D}+k_{\text {local }}\right) \frac{\rho}{1000}
$$

The friction coefficient $(f)$ depends on the water mass flow. The Reynolds number establishes whether Equation (21) or Equation (22) is used.

$$
\begin{gathered}
f=\frac{64}{R e_{D}} \quad R e<2300 \\
f=\frac{1}{\left(-1.8 \cdot \log \left(\left(\frac{6.9}{R e_{D}}\right)+\left(\frac{\epsilon}{3.7 D_{i}}\right)^{1.11}\right)\right)^{2}} \quad R e>2300
\end{gathered}
$$

The water mass flow and the cross sectional area is necessary to obtain the water velocity, however, the velocity in each channel of the cold plate is unknown. The cold plate is a multi-channel and local the losses in the entry and exit regions of the channels are too significant to be underestimated, so the hypothesis of constant mass flow along each channel stands far away from reality. An iterative non-linear calculation (friction factor depends on water velocity) is employed to obtain the hydraulic losses at the cold plate.

Some specific values for the secondary losses are as follows: $k_{\text {elbow }}=0.5, k_{\text {entry }}=0.5, k_{\text {exit }}=1$ $k_{\text {branchflow }}=1 k_{\text {lineflow }}=0.25$ [15]. Additional local losses are added to the simulation model accounting for every element of the system such as: valves, sensors, expansion tank and purgecock.

The water mass flow increment leads to a new calculation of the thermal resistance and the hydraulic losses. The water mass flow upper limit indicates the end of the simulation. Figure 3 shows the computational model proceeding; " $M$ ' stands for the water mass flow upper limit, while the lower limit must also be chosen by the user. 
The thermal resistance of each element and the consumption of the auxiliary equipment are the outputs of the computational model developed in this section.

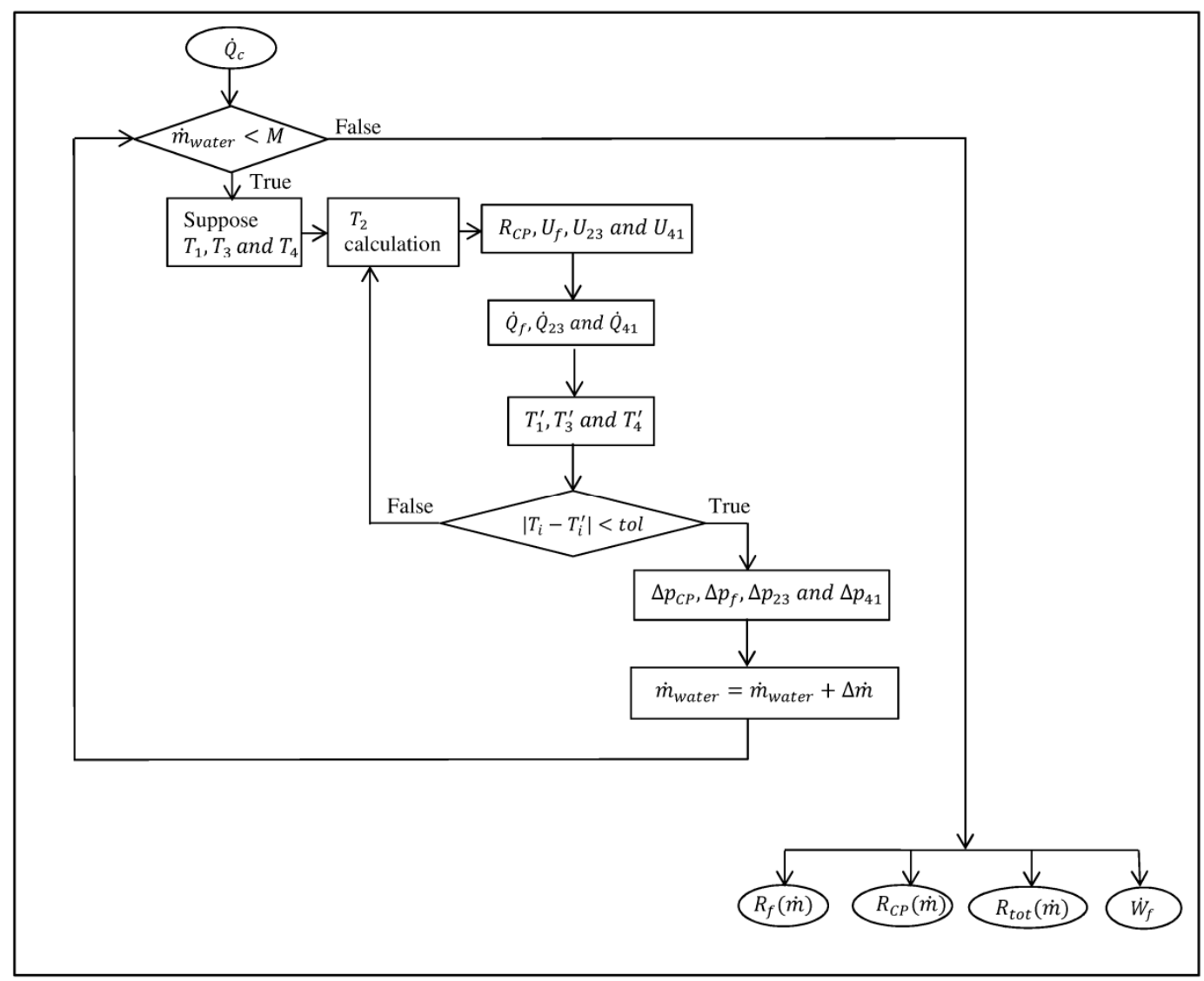

Figure 3: Schematic of the computational model.

\section{PROTOTYPE}

The prototype built to validate the computational model can be seen in Figure 4 . The main elements that are present are: the cold plate, the fan-coil and the pump. However, other elements are needed to ensure proper operation of the system and safeness: a security valve to prevent excess interior pressure, a purgecock and an expansion tank to store possible air present in the water mass flow. The interior volume of the tank is $2 \mathrm{~L}$. The heat introduced into the system comes from a hot plate, a copper plate filled with 10 circular electric resistances. The maximum power that the hot plate can emit is $2 \mathrm{~kW}$. The hot plate dimensions are similar to the cold plate working area, $195 \times 140 \mathrm{~mm}^{2}$. The assembly between these two elements ensures that every face of the hot plate is completely isolated but the one in contact with the cold plate, thus all the emitted heat goes into the cold plate.

The heat power introduced into the dissipation system and the heat dissipated through the secondary heat exchanger, the fan-coil, are calculated through the water temperature incremental, Equation (23) and Equation (24). The specific heats are evaluated at the temperature mean of each heat exchange. 


$$
\begin{aligned}
& \dot{Q}_{c}=\dot{m}_{\text {water }} C_{p}\left(T_{2}-T_{1}\right) \\
& \dot{Q}_{f}=\dot{m}_{\text {water }} C_{p}\left(T_{3}-T_{4}\right)
\end{aligned}
$$

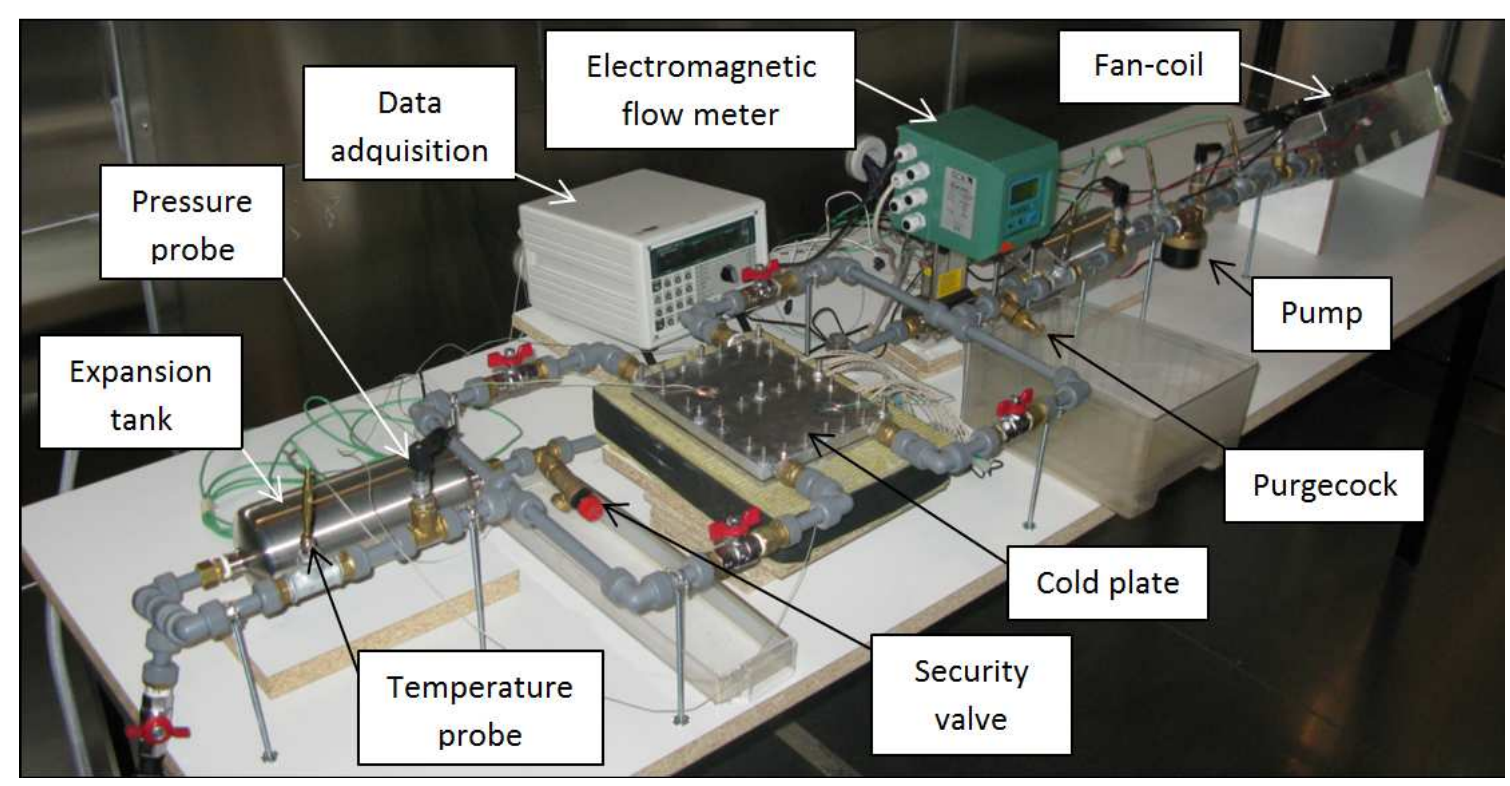

Figure 4: Prototype design of a heat dissipation system.

To measure temperature and pressure at the entries and exits of the two heat exchangers, four temperature and pressure sensors are present. An additional temperature sensor to monitor ambient temperature is also installed. Two extra temperature sensors are added to measure the temperature of the hot plate. All the temperature sensors are thermocouples of type $\mathrm{K}$ while the pressure sensors are piezo-resistive. An electromagnetic flow meter measures the water mass flow circulating along the dissipation system and a thermoanemometer measures the velocity of the air at the fan-coil. The position of every sensor can be seen more clearly in Figure 2 and their resolution and accuracy in Table 1.

The pump installed is a continuous pump which offers the possibility of choosing between four pumping levels, each of them defined by a characteristic curve. The pump is a Jabsco 59520 series. The maximum water mass flow that this pump can provide is $21 \mathrm{l} / \mathrm{min}$ with a power consumption of $21 \mathrm{~W}$.

The cold plate is a multi-channel heat exchanger. It is formed by a total of 26 channels, each of them with a length of $148 \mathrm{~mm}$ and a $6.2 \mathrm{~mm}$ hydraulic diameter. The length of each manifold is $176 \mathrm{~mm}$ and their diameter is $9 \mathrm{~mm}$. The cold plate is provided by two entries and two exits. Its external dimension is $230 \times 190 \mathrm{~mm}^{2}$. The external area accommodates the screws in charge of ensuring sealing between the two sides of the cold plate.

The fan-coil is a circular tube-continuous fin heat exchanger. 24 circular tubes, $10 \mathrm{~mm}$ diameter together with 226 continuous fins form the kernel. Three fans, JAMICON JF1225S2H, are responsible of forcing the air 
between the fins. The maximum electric power consumption of the three fans is $16.5 \mathrm{~W}$. The forced air cross sectional area is $200 \times 408 \mathrm{~mm}^{2}$.

In order to obtain equal external conditions at every experiment, the prototype is located in a climatic chamber set to $22{ }^{\circ} \mathrm{C}$.

\begin{tabular}{|ccc|}
\hline Sensor & Resolution & Accuracy \\
\hline Temperature & $0.1{ }^{0} \mathrm{C}$ & $\pm 0.5{ }^{0} \mathrm{C}$ \\
\hline Pressure & $0.01 \mathrm{bar}$ & $\pm 1 \%$ measured value \\
\hline Water flow meter & $0.01 \mathrm{l} / \mathrm{min}$ & $\pm 0.2 \%$ measured value \\
\hline Air velocity & $0.01 \mathrm{~m} / \mathrm{s}$ & $\pm 0.01 \mathrm{~m} / \mathrm{s}+3 \%$ measured value \\
\hline
\end{tabular}

Table 1: Resolution and accuracy of the sensors employed.

\section{RESULTS AND ANALYSIS}

\subsection{Experimental results}

A total of 60 experiments have been performed. The water and air mass flows are the variables of these experiments. Four different working levels for the water and five for the air have been tested, reproducing three replicas of the 20 possible experimental scenarios. The rest of the parameters, the ambient temperature and the heat flux introduced intro the dissipation system, were constant all along the experiments.

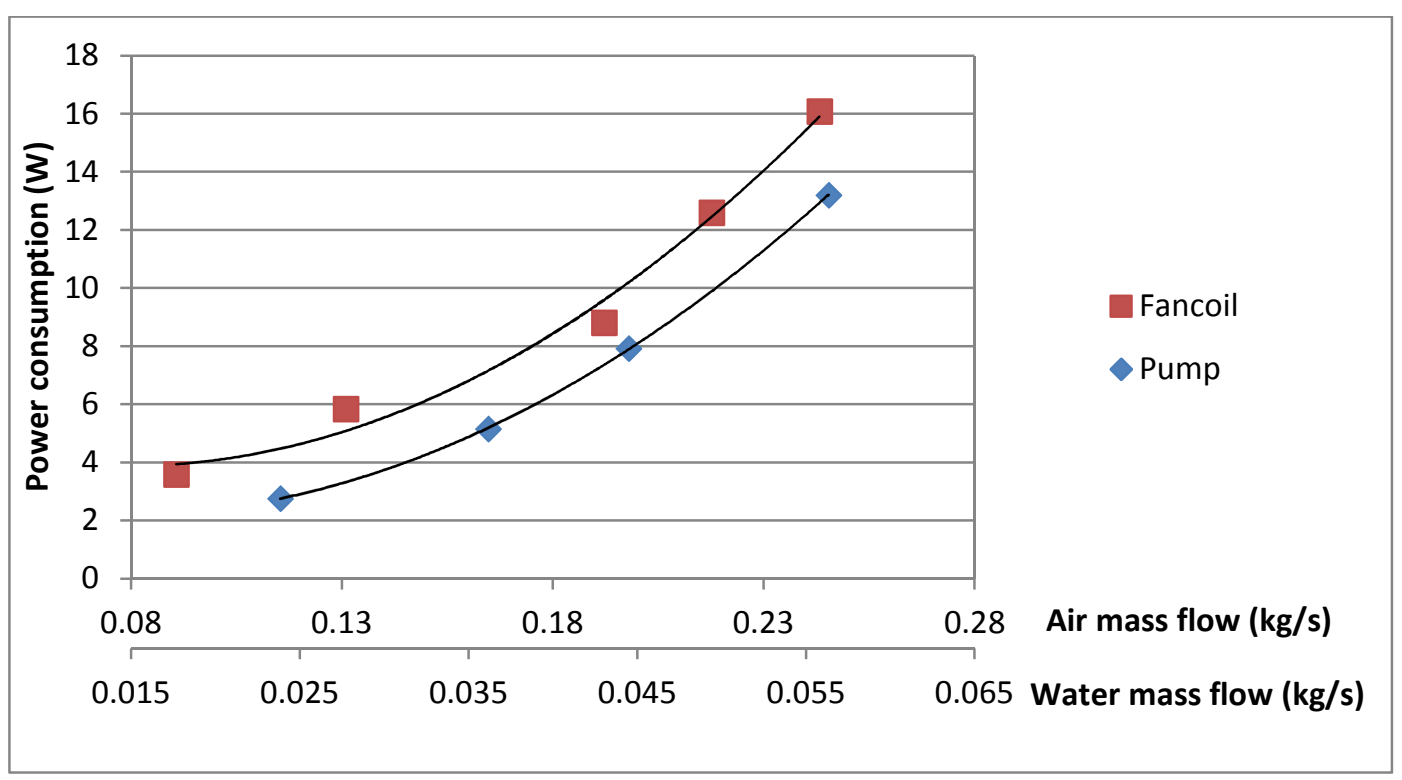

Figure 5: Working levels of the Fan-coil and the pump.

Figure 5 presents the working levels of the pump and fan-coil. The power consumption tendencies with respect to the water and air mass flows are used to quantify the decrease of the thermal resistances as the power consumption increases.

Table 2 presents the experimental temperatures of the 60 experiments made, three replicas of the 20 working points studied. The three replicas of each working point represent the deviation of the measurement 
instruments, a maximum of $0.6^{\circ} \mathrm{C}$. This deviation corroborates the accuracy of the temperature probes, $\pm 0.5^{\circ} \mathrm{C}$ as Table 1 shows. An additional column, $T_{C}-T_{a m b}$, is added. This column represents the total thermal resistance of the dissipation system, the most appreciable thermal resistance since it is the value that represents the whole refrigeration system located on the cold side of the TEG. The absolute experimental error of this indirect parameter $\left(T_{C}-T_{a m b}\right)$ is calculated through equation (25) [17] and the accuracy values of the measurement probes stated in Table 1. The maximum relative experimental value for the temperature difference is $5.34 \%$. The maximum relative experimental error represents the measurement deviation obtained when the temperature difference is calculated experimentally.

$$
\Delta y=\left[\left(\frac{\partial f}{\partial x_{1}}\right) \Delta x_{1}^{2}+\left(\frac{\partial f}{\partial x_{2}}\right) \Delta x_{2}^{2}+\cdots+\left(\frac{\partial f}{\partial x_{n}}\right) \Delta x_{n}^{2}\right]
$$

As the computational model is used to obtain the total thermal resistance and the consumption of the auxiliary equipment, the influence of the pump and the fan-coil consumption on the thermal resistances is studied based on the experimental data. Equations (1), (2) and (26) are used to obtain the main thermal resistances involved: the total resistance and the resistances of the cold plate and the fan-coil respectively. The deviation of the experimental data can be seen in Figure 6, Figure 7, Figure 8, Figure 9, Figure 10 and Figure 11. These figures represent the three main thermal resistances in function of the water and the air mass flows, and the hydraulic losses as a function of the water mass flow. The three replicas of each working point represent the experimental deviation. Every experimental result stays inside the $\pm 5 \%$ deviation range due to the measurement equipment as can be seen from Figure 6 to Figure 11.

$$
R_{f}=\frac{\frac{\left(T_{3}-T_{a m b}\right)-\left(T_{4}-T_{a m b}\right)}{\ln \left(\frac{\left(T_{3}-T_{a m b}\right)}{\left(T_{4}-T_{a m b}\right)}\right)}}{\dot{Q}_{f}}
$$

The thermal resistance of the fan-coil is dependent on both the water and the air mass flows. Figure 6 and

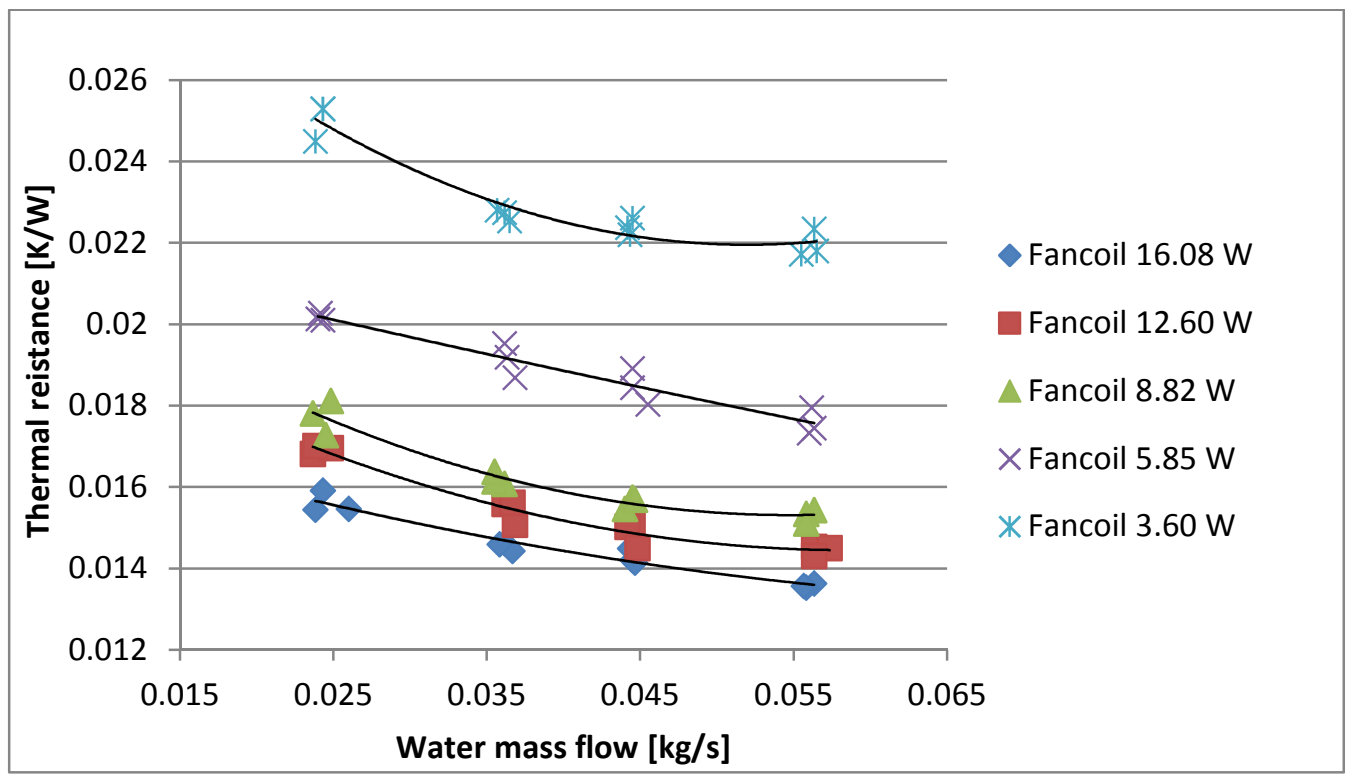

Figure 6: Fan-coil thermal resistance dependence on the water mass flow. 
Figure 7 indicate stronger dependence with the air mass flow than with the water. The global heat transfer coefficient is composed by internal and external convection and the conduction. In this case, the internal convection is water-forced while the external convection is forced with air. The convective coefficient of the water is higher than the air one, so that, the external convection is defining the heat transfer. The improvement of the external convection results in a marked thermal resistance reduction.

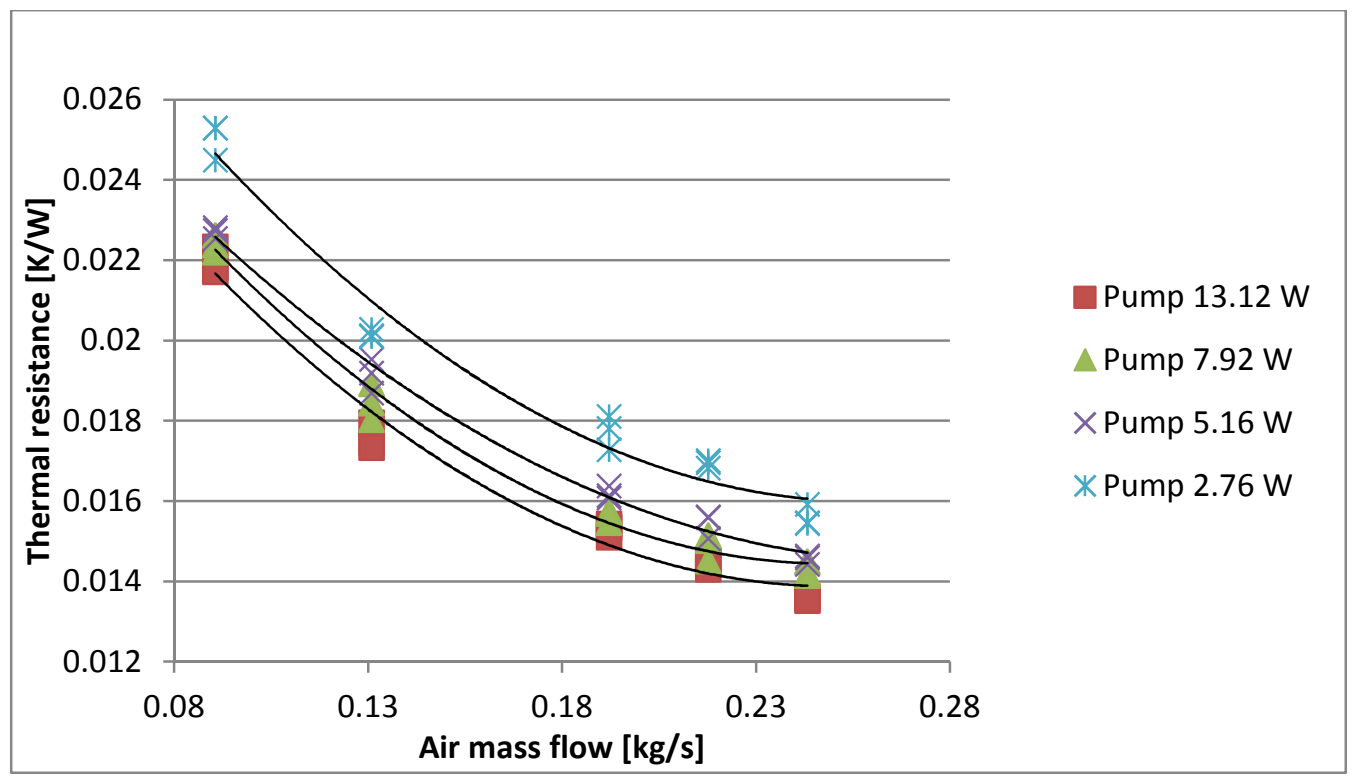

Figure 7: Fan-coil thermal resistance dependence on the air mass flow.

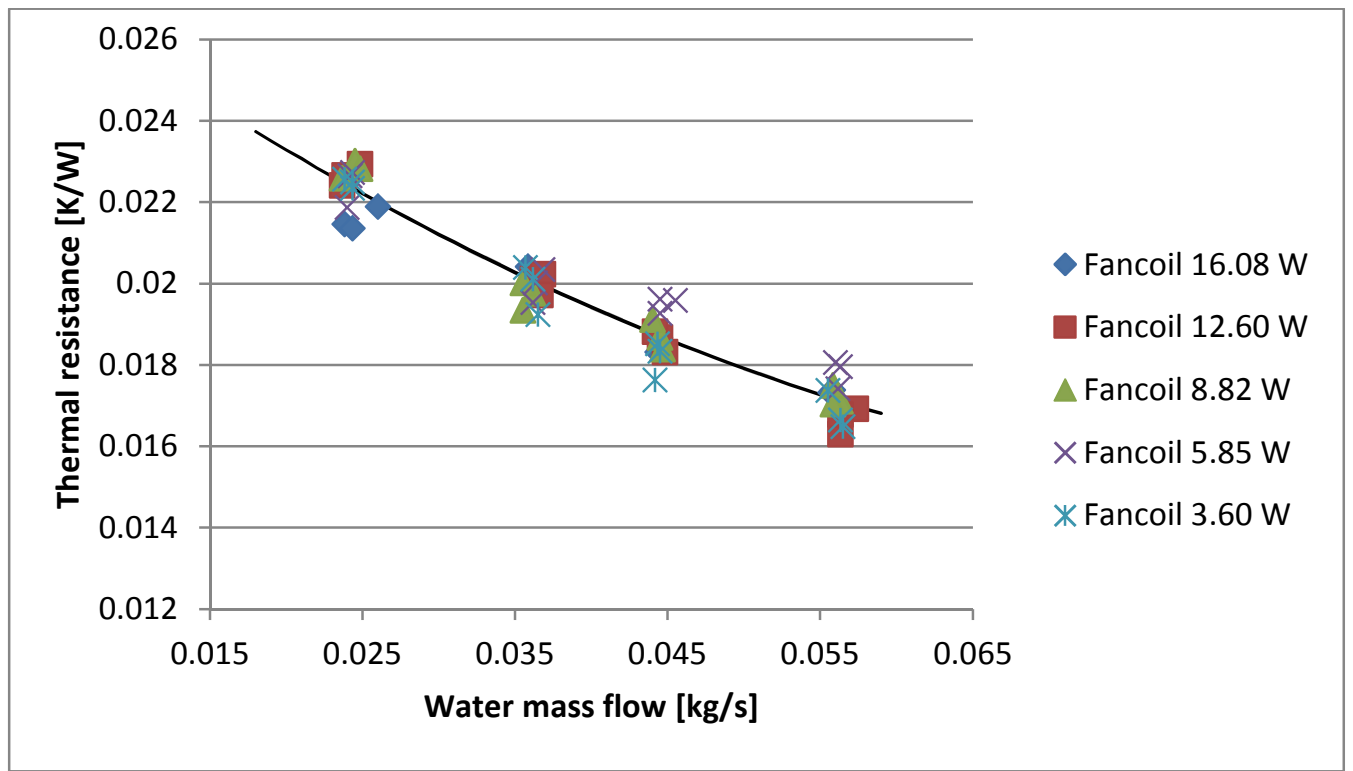

Figure 8: Cold plate thermal resistance dependence on the water mass flow.

The resistance of the cold plate only depends on the water mass flow as presented in Figure 8. The air mass flow causes changes in the temperature of the water. The Nusselt number is dependent on the Reynolds and 
Prandtl numbers. The Reynolds number is a function of the water mass flow and the fluid properties, including the Prandtl number, dependent on the temperature of the water. As the temperature changes are not too significant, the thermal resistance of the cold plate is independent with the air mass flow. The variability between points is due to the experimental deviation, a $\pm 5 \%$ as it was stated at the beginning of the "Results and analysis" section.

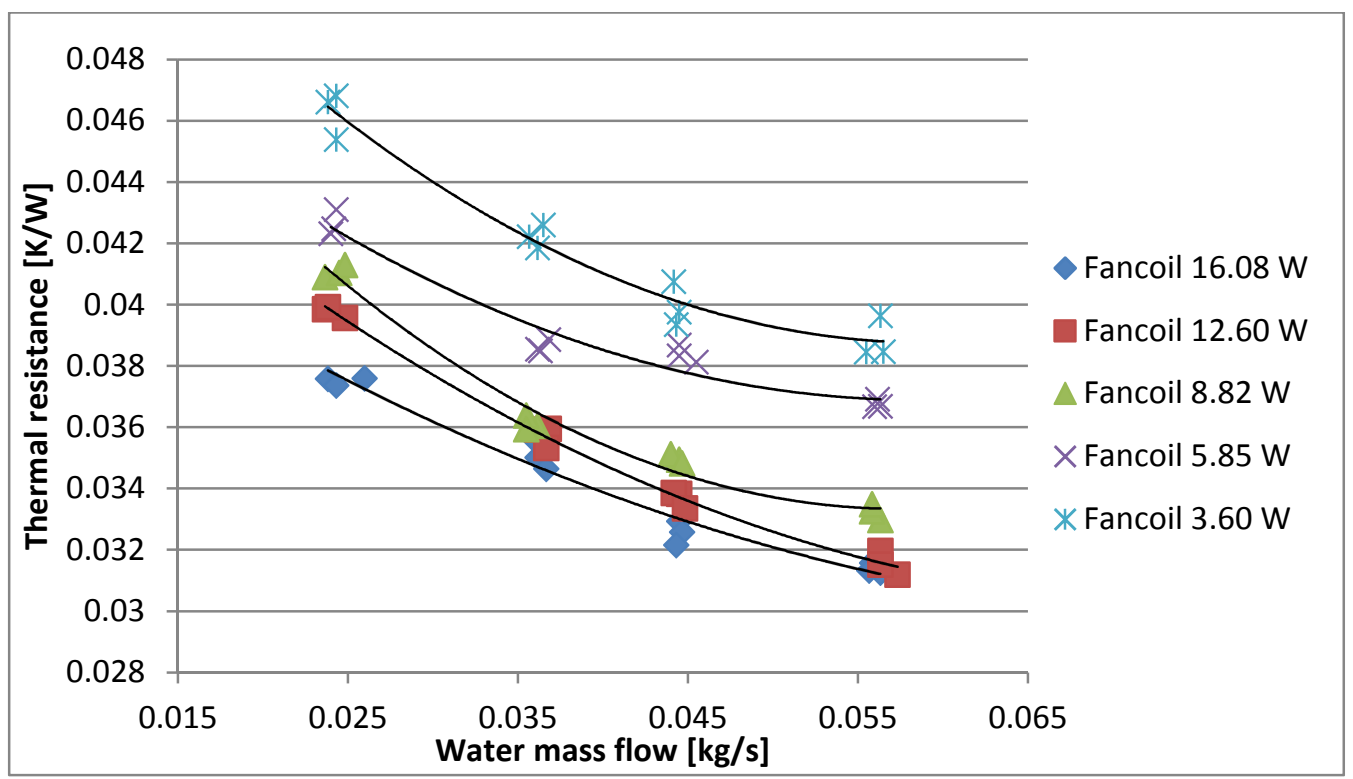

Figure 9: Total thermal resistance dependence on the water mass flow.

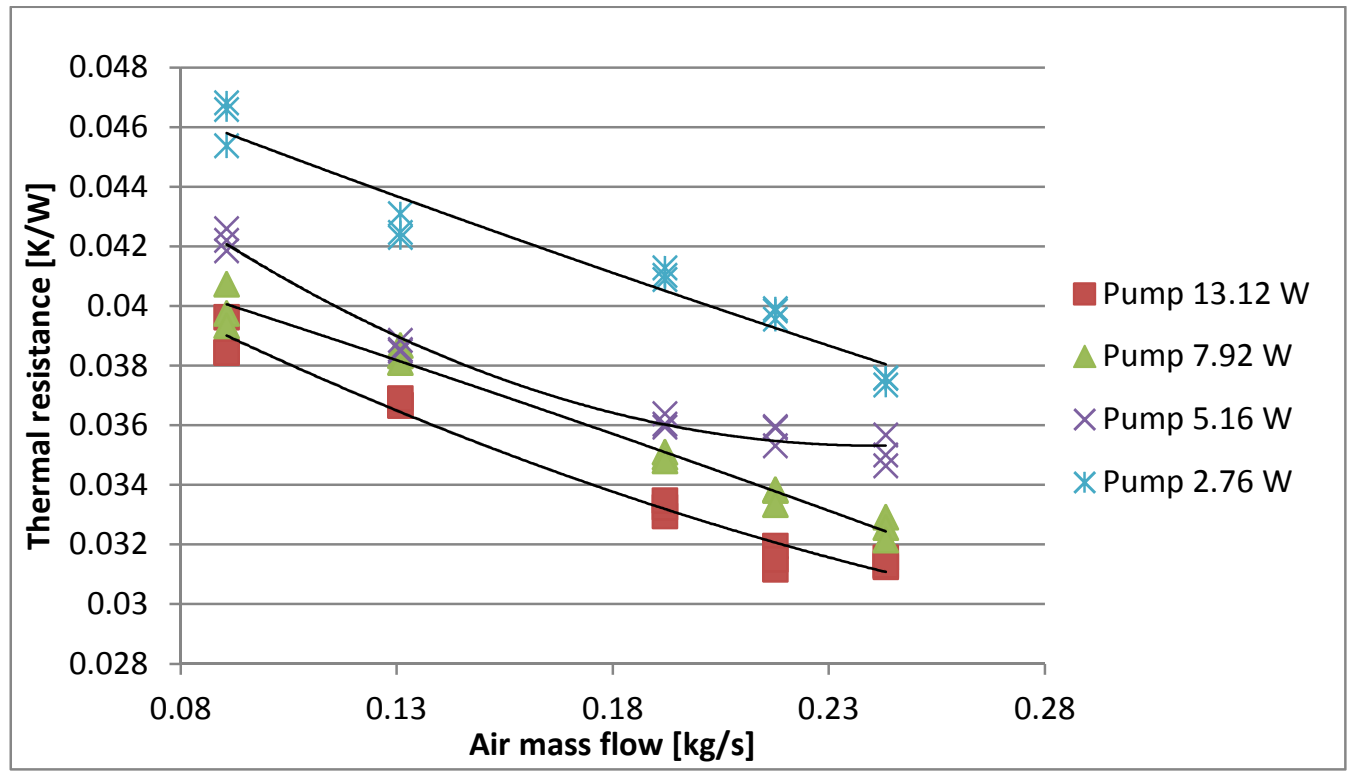

Figure 10: Total thermal resistance dependence on the air mass flow.

Figure 9 shows the dependence of the total thermal resistance on the water mass flow while Figure 10 presents its air mass flow dependency. The values of the total thermal resistance, Figure 9 and Figure 10, are significantly higher than the ones of the cold plate. Optimizing the dissipation system does not have to solely 
focus on the thermal cold plate optimization, but on the optimization of the system as a whole. The total thermal resistance strong dependence on the air mass flow displays the necessity of taking into account the fan-coil for thermal calculations.

Changing the working level of the pump from 1 to 2 produces a $51 \%$ increase in the water mass flow (from $0.0239 \mathrm{~kg} / \mathrm{s}$ to $0.0361 \mathrm{~kg} / \mathrm{s}$ ) and a power increase of the $87 \%$. The cold plate thermal resistance reduction is 12 $\%$ while the total resistance decreases a $10 \%$, being the fan-coil set to level $1(3.6 \mathrm{~W})$. On the other hand, rising the pump level from 3 to 4 , the reduction of the total resistance is the $3 \%$, a $9 \%$ decrease on the cold plate resistance. The increase of a $65 \%$ in the power consumption of the pump leads to an increase of the $26.5 \%$ in the water mass flow. Consequently, the effects on the total thermal resistance of increasing the working level at low levels are higher than in the upper levels.

The fan-coil and the total resistance decrease $18 \%$ and $7 \%$ respectively if the level of the fan-coil is increased from 1 to 2 (the pump working level is set to $4,13.12 \mathrm{~W}$ ). The consumption increases a $62.5 \%$ and the air mass flow a $43 \%$. If the fan-coil is set to level 5 , coming from level 4 , the consumption increases a 27 $\%$, the water mass flow a $12 \%$ and the resistance reduction is the $2 \%$ and $3 \%$ for the fan-coil and total resistances respectively. The tendency of the total thermal resistance is quite linear with the fan-coil power consumption.

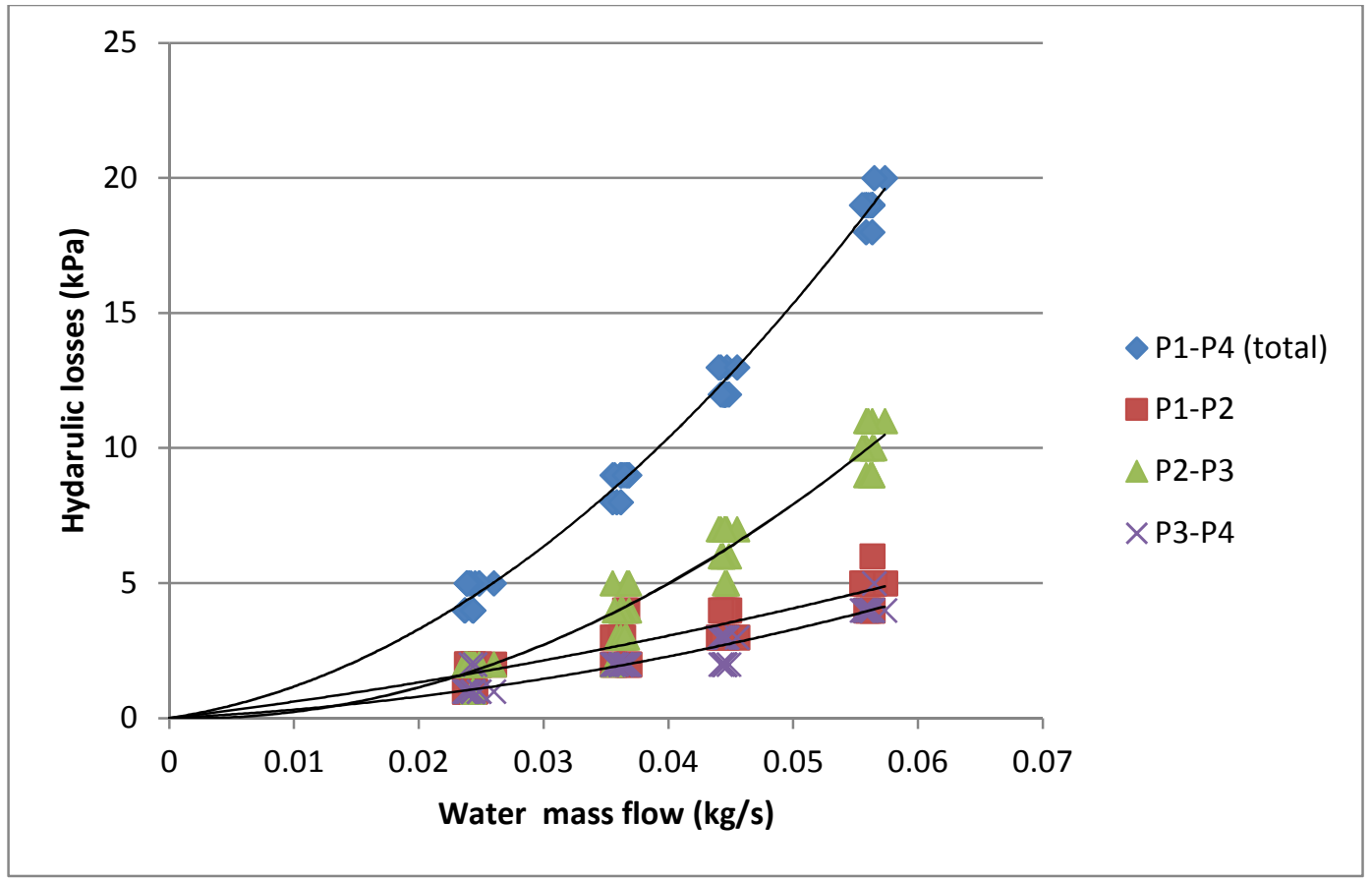

Figure 11: Hydraulic losses for different elements of the system.

Figure 11 presents the losses characteristic curve of the system $(P 1-P 4)$, and the characteristic curves of different parts of the dissipation system. Each sensor position can be seen in Figure 2. The intersection of the characteristic curve of the pump with the hydraulic losses curve of the system obtains the operating point, the 
water mass flow that circulates along the dissipation system. Using a high power demanding pump, a high water mass flow could have been achieved obtaining a very low thermal resistance. In this case, the power consumption would be very high leading to a non-desirable solution, lower net thermoelectric generation.

The hydraulic losses of the fan-coil $(P 3-P 4)$ are the smallest ones, but the only ones that just take into account a single element of the system. The hydraulic losses between point 1 and $2(P 1-P 2)$ take into account the cold plate itself, the piping needed to circulate the water, a purgecock and a temperature sensor. The hydraulic losses between point 2 and $3(P 2-P 3)$ represent the losses due to the additional elements of the system, an expansion tank, a security valve, piping, elbows and temperature and mass flow sensors. These results present the magnitude of the local losses.

As Figure 11 shows, each hydraulic loss is essential to compute the total hydraulic losses. However, a final design would not need to include so many additional elements, so that the total hydraulic losses would be reduced drastically.

\subsection{Computational model validation}

To obtain the simulated values the experimental water mass flow is introduced into the computational model. The total computational time needed to calculate the 60 different cases is 1.15 seconds employing a $3.10 \mathrm{GHz}$ CPU. It takes a media of 0.019 seconds to calculate the thermal resistances and the total hydraulic losses of a particular case.

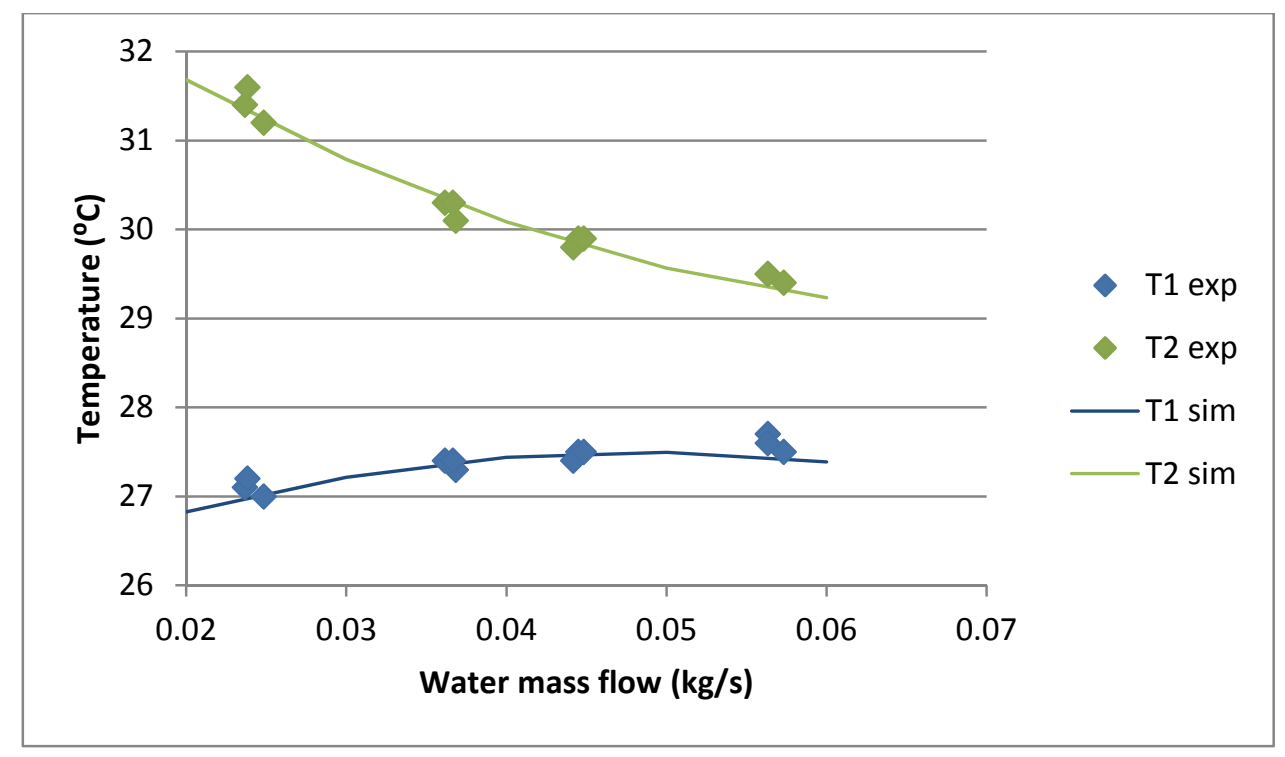

Figure 12: Experimental temperature, $T_{1 \exp }$ and $T_{2 \exp }$, and computationally simulated temperatures, $T_{1 \operatorname{sim}}$ and $T_{2 \operatorname{sim}}$ of the cold plate.

The temperature tendencies are well reproduced by the computational model as Figure 12 and Figure 13 show. The absolute error of the temperatures is obtained through Equation (27). This error is bounded by its minimum, $-0.87^{\circ} \mathrm{C}$, and its maximum, $0.42^{\circ} \mathrm{C}$, as can be seen in Table 2 . In the case of the temperature 
difference that represents the total thermal resistance, the relative error has been calculated, the range where each error can be found is [- 3.90-4.27\%]. A very small temperature drops exist between $T_{2}$ and $T_{3}$ and between $T_{4}$ and $T_{1}$, the areas in between the cold-plate and the fan-coil as Figure 12 and Figure 13 present. Figure 2 schematically presents the elements included in each area; pipes, measurement probes and safety elements. The characteristics of the prototype determine the heat emitted to the ambient, material and length of the pipes. Nevertheless, in an installation where the length of the pipes is considerable and the material of the pipes is a better heat conductor, the heat emitted to the ambient by these areas can achieve important values.

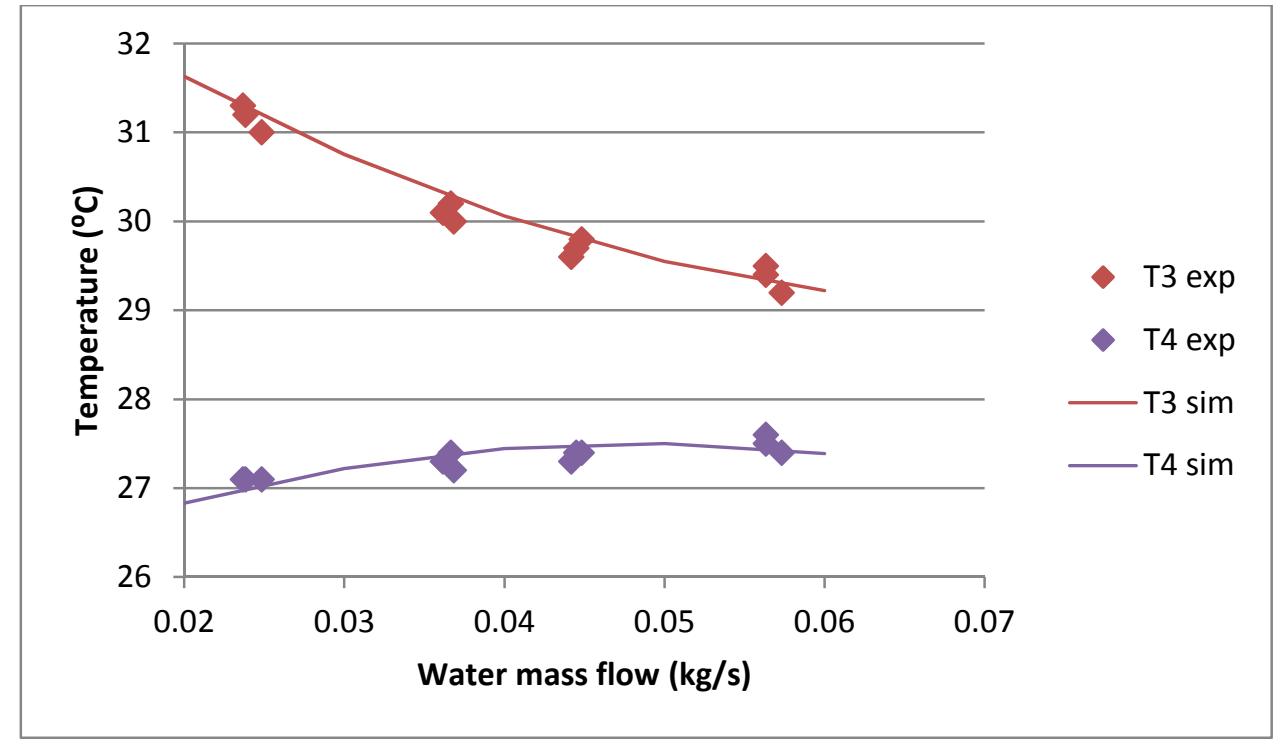

Figure 13: Experimental temperature, $T_{3 \exp }$ and $T_{4 \exp }$, and computationally simulated temperatures, $T_{3 \operatorname{sim}}$ and $T_{4 \operatorname{sim}}$ of the fan-coil.

$$
\begin{gathered}
\text { Absolute error }=\text { Value }_{\text {exp }}-\text { Value }_{\text {sim }} \\
\text { Relative error }=\frac{\text { Value }_{\text {exp }}-\text { Value }_{\text {sim }}}{\text { Value }_{\text {exp }}} \cdot 100
\end{gathered}
$$

Figure 14, Figure 15, Figure 16 and Figure 17 show the computational model accuracy. Figure 14, Figure 15 and Figure 16 present the computational simulated values versus the experimental values of the resistances of the fan-coil, the cold plate and the total one, respectively. As can be seen, every simulated value stays in a $\pm 7 \%$ error range, thus the accuracy of the computational model is $93 \%$. 


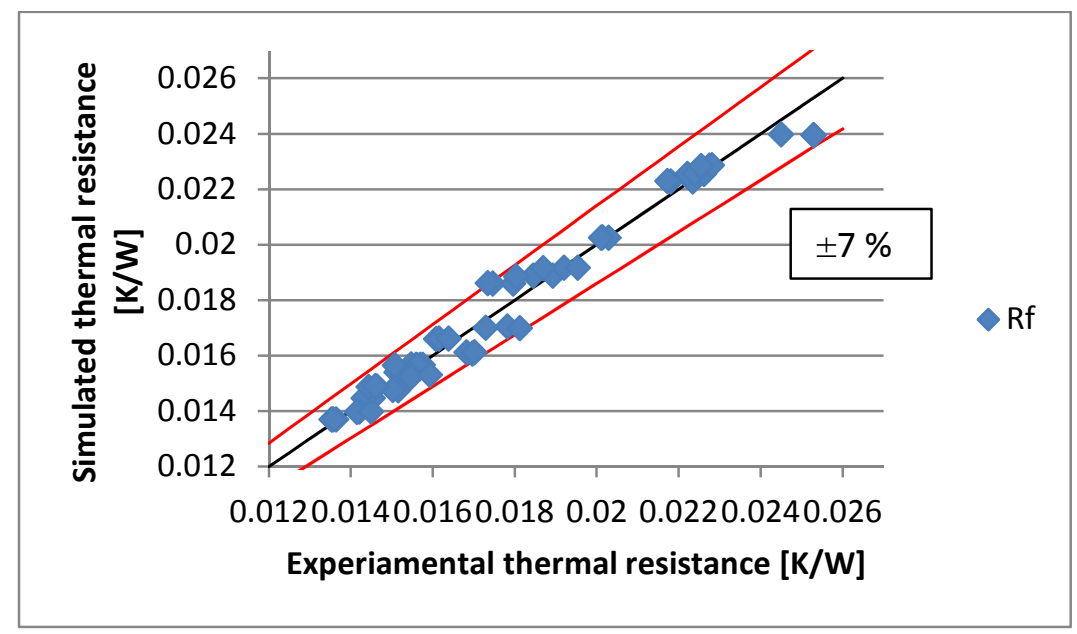

Figure 14: Fan-coil simulated thermal resistance in the $\pm 7 \%$ experimental resistance range.

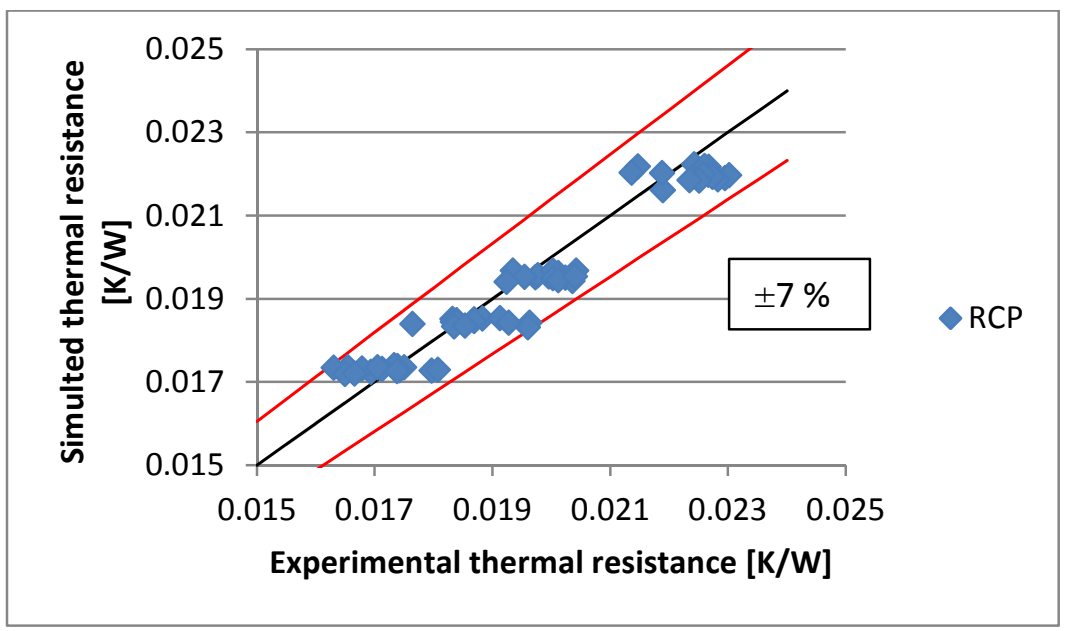

Figure 15: Cold plate simulated thermal resistance in the $\pm 7 \%$ experimental resistance range.

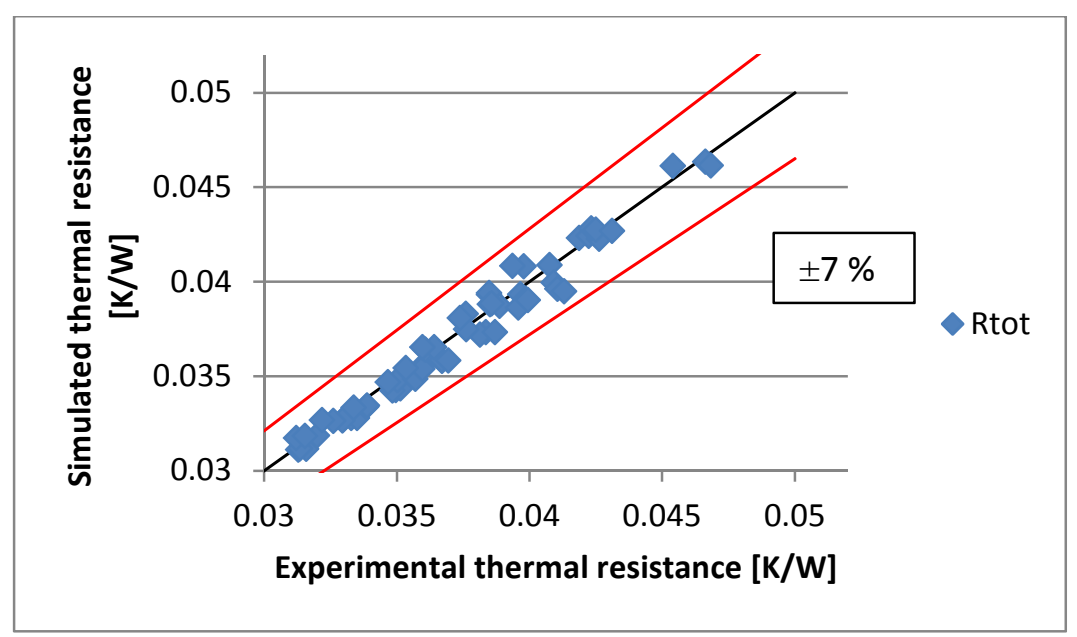

Figure 16: Total simulated thermal resistance in the $\pm 7 \%$ experimental resistance range including the water mass flows as inputs

The total resistance is meant to be introduced into the TEG computational model to obtain the net power generation. Figure 17 presents the statistical study of the error; the standardized bias and kurtosis are -0.3116 
and -0.3188 respectively, so the assumption of normality can be made. As Figure $17 \mathrm{~b}$ ) shows, the standardized errors stay in between the -3 and +3 range; just 3 errors are higher than $|2|$. The mean of the error is 0.22 .
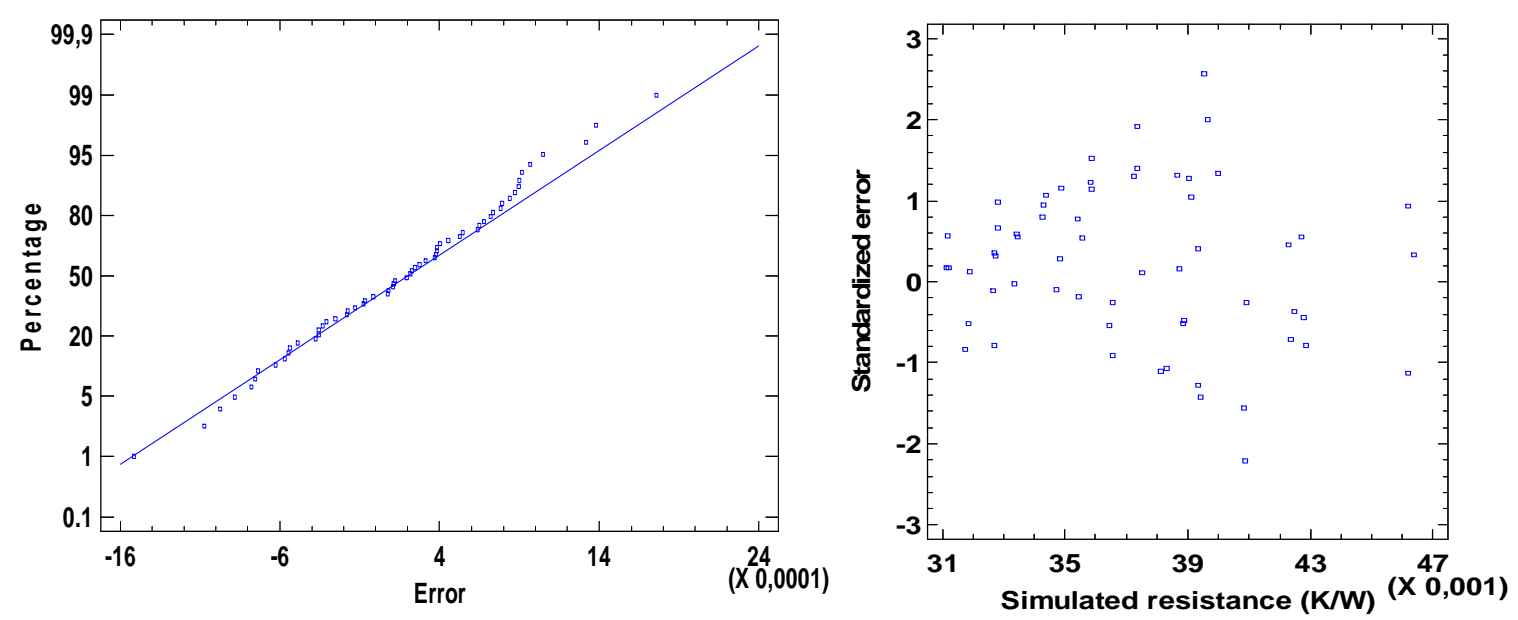

Figure 17: Statistical study of the error introducing the exact water mass flow, a) Normal probability plot, b)

Standardized errors vs the simulated thermal resistance

Figure 18 presents the total hydraulic losses predictability of the computational model. The computational model maximum error is $\pm 7 \%$. An accurate prediction of the hydraulic losses is vital for pump design.

The rapidity of the computational model and its versatility converts it into an optimization tool to dissipation design. Changes in geometry, auxiliary equipment or ambient conditions can be introduced and evaluated seeking net power generation maximization.

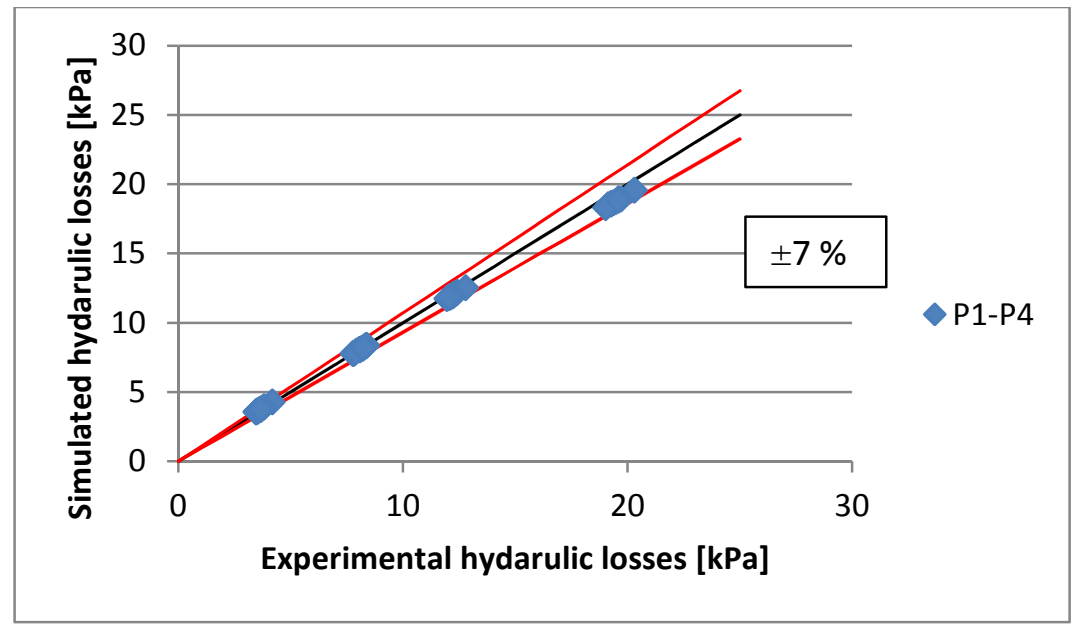

Figure 18: Total simulated hydraulic losses in the $\pm 7 \%$ experimental losses range

The computational model also obtains accurate results (a maximum error of $\pm 7 \%$ ) if the pump characteristic curve is introduced, Figure 20 depicts this fact. The pump curve is determinant, introducing an overestimated curve would lead into a bigger water mass flow operating point, so that a smaller thermal resistance than the measured value. 


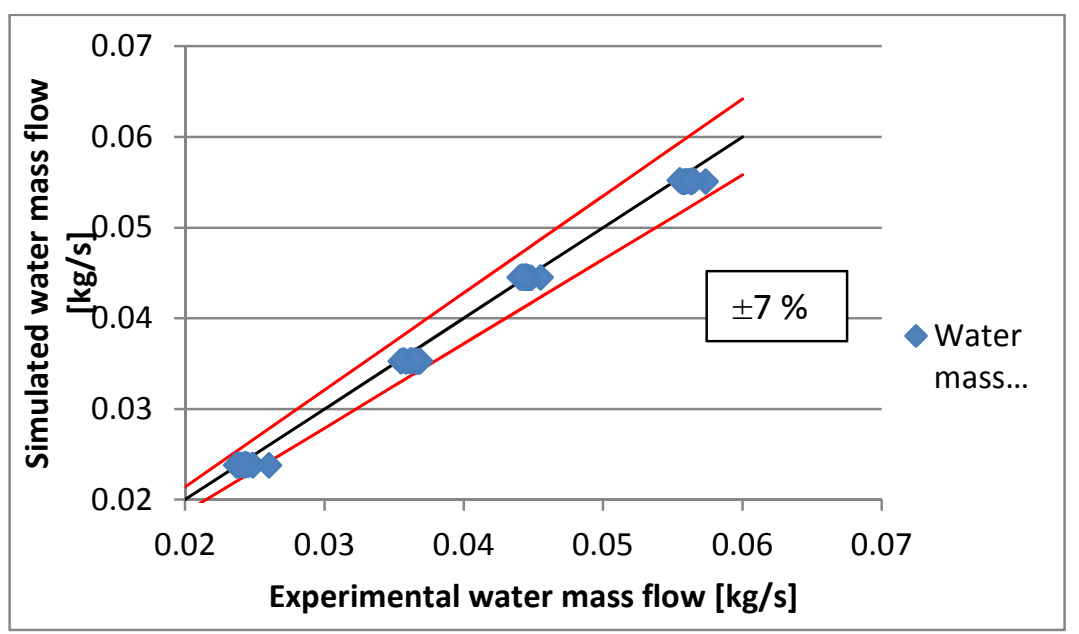

Figure 19: Simulated water mass flow in the $\pm 7 \%$ experimental mass flow range

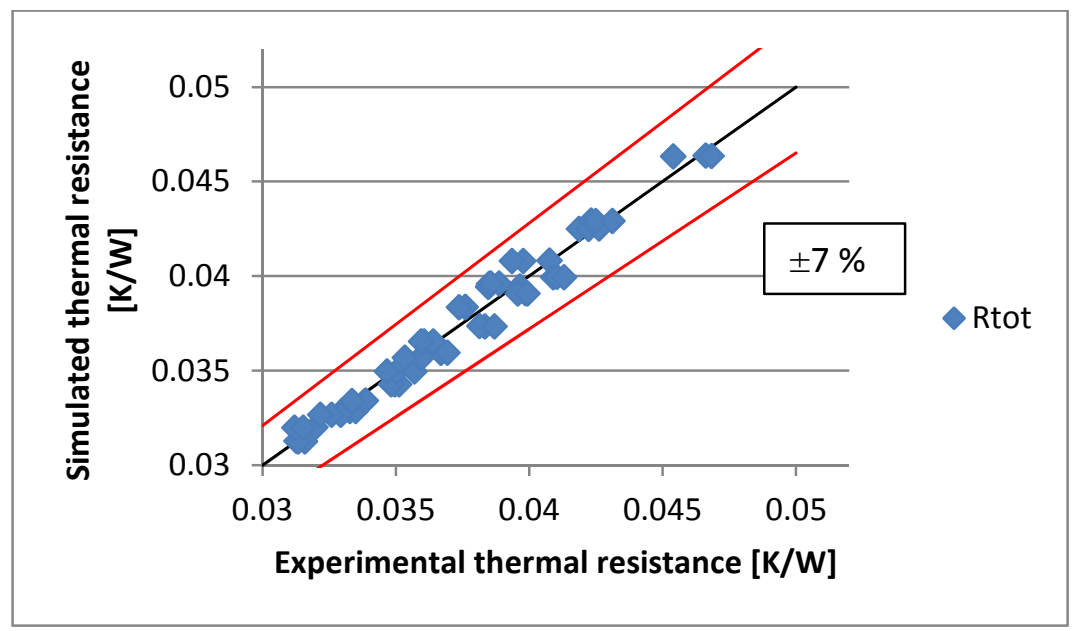

Figure 20: Total simulated thermal resistance in the $\pm 7 \%$ experimental resistance range including the pump characteristic curves as inputs

An accurate water mass flow prediction is vital for resistances prediction. Figure 19 provides the simulated values versus the experimental data, the accuracy is $93 \%$. The computational time to obtain these results grows. The model has to calculate in each case the outputs in a range of water mass flows. The bigger the number of calculated points inside the flow range the better results are obtained. The total computational time for the 60 cases is 26.26 seconds. This value was expectable because each case needs to compute 26 water mass flow points in order to obtain the operation point; the exact water mass flow that circulates along the system.

The statistical study of the error is presented in Figure 21. The standardized bias and kurtosis are -0.3429 and -1.4276 respectively and the standardized errors are all included in the range between -2 and 2 with the exception of a particular error with a value of 2.10. The statistical study on the errors assures that the model is valid with a maximum error of $\pm 7 \%$ regardless of whether the mass flow or the pump curve is introduced. 

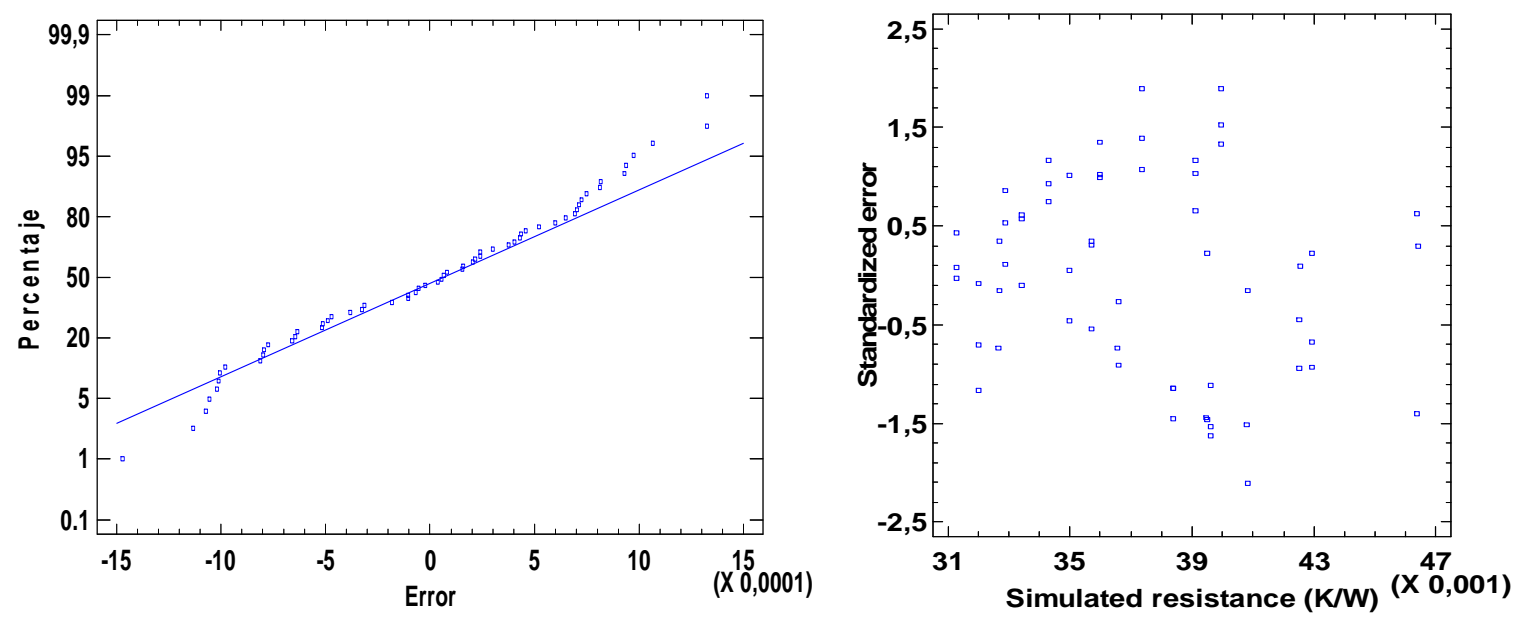

Figure 21: Statistical study of the error introducing the characteristic curve of the pump, a) Normal probability plot, b) Standardized errors vs the simulated thermal resistances

\section{OPTIMIZATION STUDY}

The computational model presented and validated in the above sections procures the total thermal resistance and the auxiliary power consumption of a heat dissipation system involving water as a heat carrier. In thermoelectricity, the thermal resistances on both sides of the TEMs are important to be as low as possible, but at the same time, it is essential to minimize the power consumption of the auxiliary equipment, therefore, a compromise should be reached. The validated thermoelectric generation computational model [5] is used to conduct this study.

\subsection{Computational optimization}

The interaction of the two validated computational models is used to search the optimum, the maximum net generation working point. An expression of the total thermal resistance of the prototype thanks to the computational methodology presented in this work has been obtained. The expression is bounded by the upper and lower experimental limits of the water and air mass flows $0.02383<\dot{m}_{\text {water }}<0.05633$ and $0.0906<\dot{m}_{\text {air }}<$ 0.2432 .

$$
\begin{aligned}
R_{\text {tot }}\left(\dot{m}_{\text {water }}, \dot{m}_{\text {air }}\right) & =0.044-0.5782 \dot{m}_{\text {water }}-0.0015 \ln \left(\dot{m}_{\text {air }}\right)+4.2272 \dot{m}_{\text {water }}^{2} \\
& +0.0016 \ln \left(\dot{m}_{\text {air }}\right)^{2}-0.01 \dot{m}_{\text {water }} \ln \left(\dot{m}_{\text {air }}\right)
\end{aligned}
$$

Equation (29) presents the dependency of the total thermal resistance on the water and air mass flows.. This equation is introduced into the thermoelectric generation computational model as the thermal resistance of the dissipator of the cold side. A temperature of $250^{\circ} \mathrm{C}$ for the heat source, a ambient temperature of $15^{\circ} \mathrm{C}$ and a thermal resistance of $0.033 \mathrm{~K} / \mathrm{W}$ for the heat exchanger located on the hot side have been simulated.

The thermoelectric generation is presented in an equation, Equation (30), as a function of the water and air mass flows. The thermoelectric generation is maxima at the upper bounds of the water and air mass flows. Equation (31) addresses the net generation; the consumption of the auxiliary equipment has been subtracted 
from the thermoelectric generation. In this case the optimum net power corresponds to 0.0319 and $0.1315 \mathrm{~kg} / \mathrm{s}$ for the water and air mass flows respectively. The net power production of the optimal point equals $41.63 \mathrm{~W}$. Figure 22 presents both generations highlighting the importance of introducing the auxiliary consumption into the calculation. Whereas the lowest thermal resistance generates the highest thermoelectric power, the optimum net generation power is close to the opposite point, the smallest auxiliary consumption.

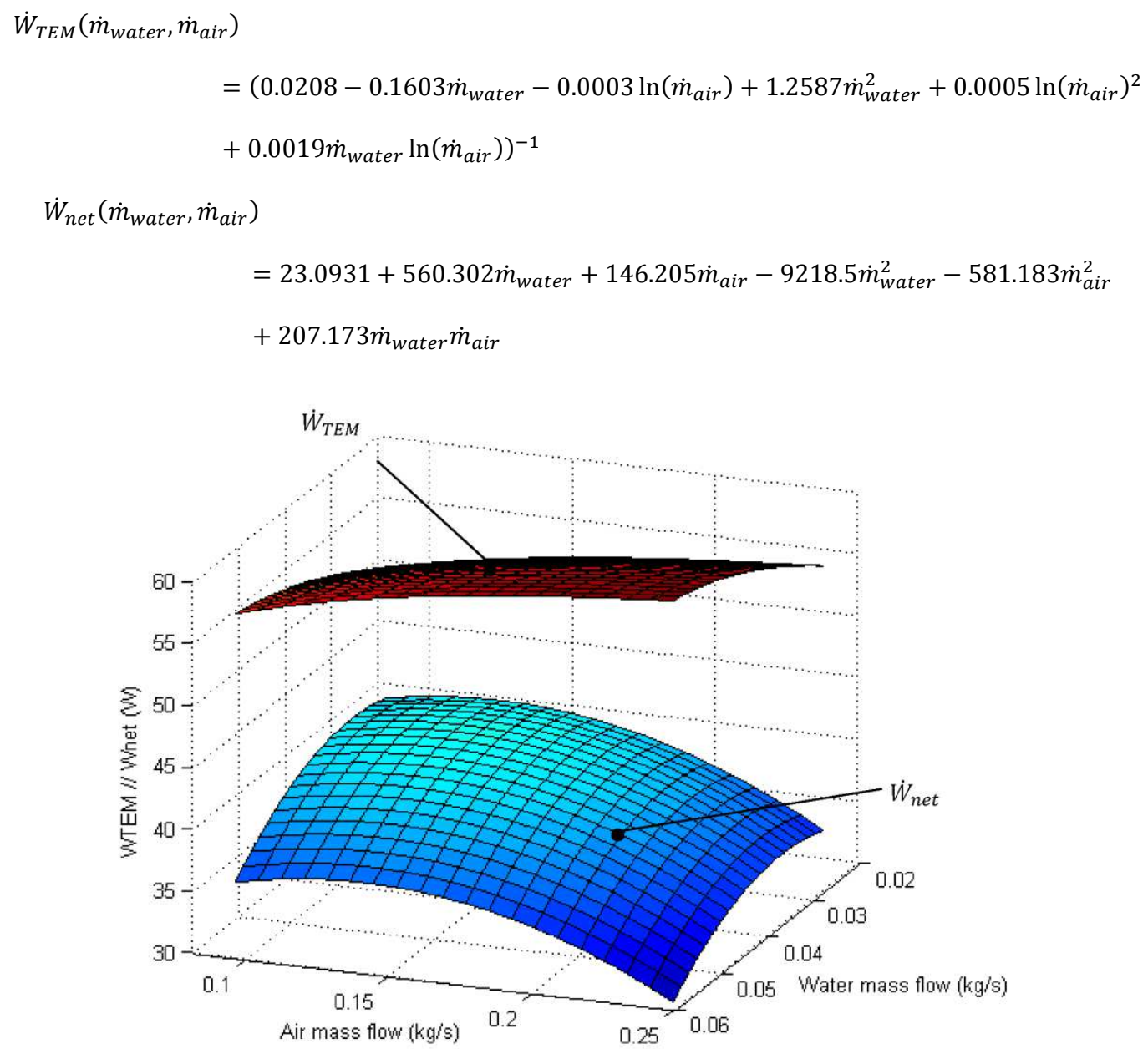

Figure 22: Thermoelectric and net generated power computationally calculated

\subsection{Optimal experimental point}

The same study as in the previous section has been made. In this case the resistance values of the dissipator located on the cold side are experimentally obtained. Four water mass flows included in the range $(0.02383-$ $0.05633)$ and five air mass flows $(0.0906-0.2432)$ have been chosen to obtain the thermal resistances. These twenty experimental points correspond with the experiments made to validate the computational model developed in this work. The same values of ambient temperature, heat source temperature and thermal resistance of the dissipator of the hot side have been used, $15^{\circ} \mathrm{C}, 250^{\circ} \mathrm{C}$ and $0.033 \mathrm{~K} / \mathrm{W}$ respectively. The thermoelectric generation as well as the net generation can be seen in Figure 23. The optimal working area corresponds to the two lowest water and air mass flows $\left(0.02383<\dot{m}_{\text {water }}<0.03622,0.0906<\dot{m}_{\text {air }}<\right.$ 
0.1420). The net generation is approximately $40 \mathrm{~W}$ for each point in this area. It can be seen that the computational and experimental optimal values agree.

Figure 23 presents the thermoelectric and net power generations. As the pump and the fan-coil consumption increase the thermoelectric power generation increases also. However, the net generation does not have this tendency. The consumption of the auxiliary equipment is not negligible, being decisive for optimization seeking. The net thermoelectric generation of the optimal point is $40.73 \mathrm{~W}$ while the smallest thermal resistance working point, the point in which the power consumption of the auxiliary equipment is the highest, has a power generation of 28.99 W. Smaller mass flows of air and water obtain an increase of the $40 \%$ with respect to the best thermal scenario, the smallest thermal resistance obtained through the highest air and water mass flows.

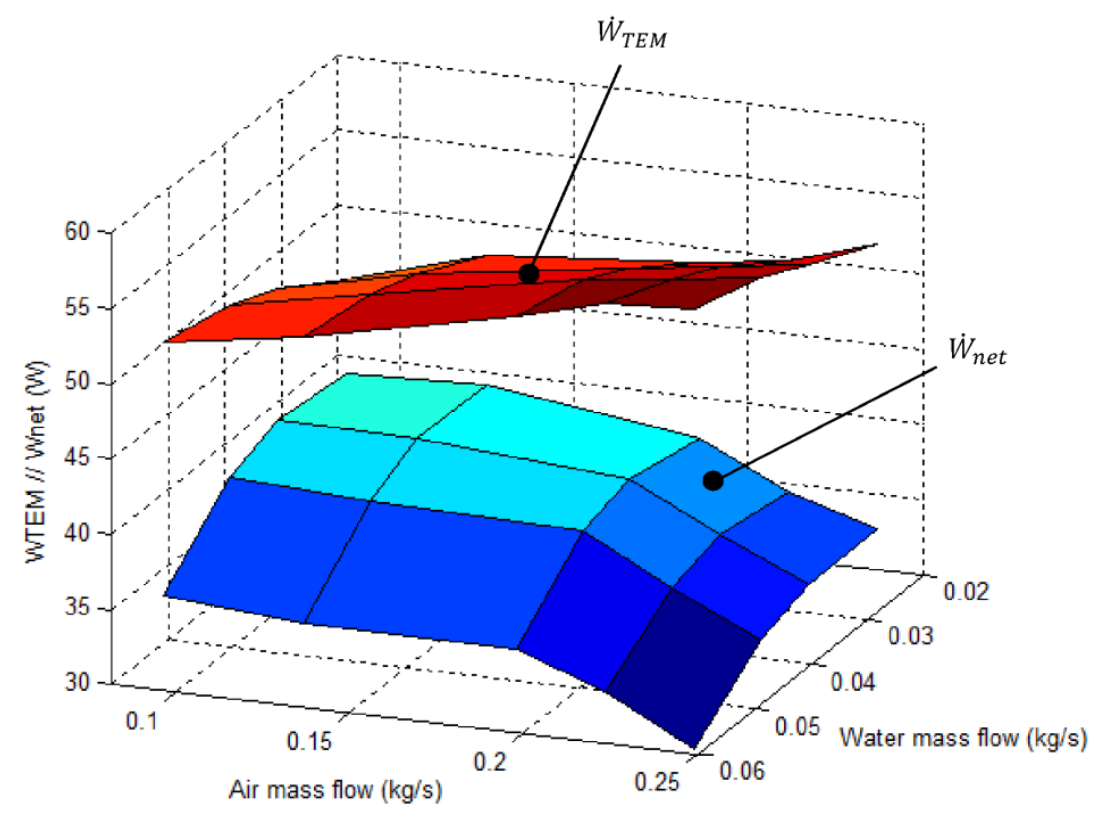

Figure 23: Thermoelectric and net generated power obtained from the experimental data

\section{CONCLUSIONS}

A computational model, which represents a whole dissipation system for a TEG, has been created. The main elements that this model has are: a multi-channel heat exchanger located on the cold side of the TEM, a secondary heat exchanger in charge of reducing the temperature of the water, a pump to impulse the water and pipes to connect the elements.

A prototype has been built. The prototype, as the computational model, includes each element needed in a closed dissipation system, apart from the necessary measurement instrument needed to collect the data.

It has been proved that it is necessary to include the secondary heat exchanger, the fan-coil, and the piping into the thermal and hydraulic calculations. The total thermal resistance and the hydraulic losses are not only determined by the cold plate, but also by the rest of the elements of the system, the fan-coil, the piping and the 
additional elements. So that, every element of the system should be included into the calculations to obtain accurate results.

An $87 \%$ pump consumption increase leads to a $10 \%$ total thermal resistance reduction at low pump levels. A $65 \%$ rise, at high pump levels, obtains a thermal reduction of the $3 \%$. On the other hand, a $62.5 \%$ increase in the fan-coil consumption obtains a $7 \%$ total resistance decrease at any working level.

The computational model accuracy, introducing the exact water mass flow value, or with the pump characteristic curve, is $93 \%$. The statistic study of the errors verifies the model. The total thermal resistance and the auxiliary equipment consumption introduced into the validated TEG computational model [5], obtain thermoelectric net power generations, the maximization objective. Thus, an optimization tool for dissipation systems involving refrigerants has been designed.

The optimal configuration, the configuration that obtains the highest net power does not match with the configuration with the smallest total thermal resistance. The power consumption of the auxiliary equipment needed to obtain small thermal resistances consumes a big part of the generated power leading to undesirable situations. The optimum experimental point obtains an increase of the $40 \%$ on the net generated power with respect to the smallest resistance experimental point.

\section{ACKNOWLEDGEMENTS}

The authors are indebted to the Spanish Ministry of Economy and Competitiveness, and European Regional Development Fund for the economic support to this work, included in the DPI2011-24287 research project.

\section{REFERENCES}

[1] Rowe DM. Thermoelectrics Handbook Macro to Nano. 1st ed. Florida, Boca Raton: CRC Press; 2006.

[2] Friedensen VP. Space nuclear power: technology, police and risk considerations in human missions to Mars. Acta Astronaut 1998; 42:395-409.

[3] Yu C, Chau KT. Thermoelectric automotive waste heat energy recovery using maximum power point track. Energ Convers Manage 2009; 50:1206-12.

[4] LaGrandeur J, Crane D, Hung S, Mazar B, Eder A. Automotive waste heat conversion to electric power using Skutterudite, TAGS, PbTe and BiTe. Int conf Thermoelec 2006; p. 343-8.

[5] Astrain D, Vián JG, Martínez A, Rodríguez A. Study of the influence of heat exchangers' thermal resistances on a thermoelectric generation system. Energy 2010; 35:602-12.

[6] Agostini B, Fabbri M, Park JE, Wojtan L, Thome JR, Michel B. State of the Art of High Heat Flux Cooling Technologies. Heat Transfer Eng 2007; 28: 258-81. 
[7] Samba A, Louahlia-Gualous H, Le Masson S, Nörterhäuse D. Two-phase thermosyphon loop for cooling outdoor telecommunication equipments. Appl Therm Eng 2013; 50:1351-60.

[8] Zhou ZG, Zhu DS, Wu HX, Zhang HS. Modeling, experimental study on the heat transfer characteristics of thermoelectric generator. J Therm Sci 2013; 22:48-54.

[9] Rezania A, Rosendahl LA, Andreasen SJ, Experimental investigation of thermoelectric power generation versus coolant pumping power in a microchannel heat sink. International Communications in Heat and Mass Transfer 2012; 39:1054-8.

[10] Rezania A, Rosendahl LA. Thermal effect of a thermoelectric generator on parallel microchannel heat sink. Energy $2012 ; 37: 220-27$.

[11] Zhou S, Sammakia BG, White B, Borgesen P. Multiscale modeling of thermoelectric generators for the optimized conversion performance. Int J Heat Mass Tran 2013; 62: 435-44.

[12] Baker C, Vuppuluri P, Shi L, Hall M. Model of heat Exchanger for Waste Heat Recovery form Diesel Engine Exhaust for Thermoelectric Power Generation. J Electron Mater 2012; 41: 1290-7.

[13] Frédéric JL, Sempels EV, Lalande-Bertrand N. A study on heat transfer enhancement using flow channel inserts for thermoelectric power generation. Energ Convers Manage 2013; 75: 532-41.

[14] Zhou S, Sammakia BG, White B, Borgesen P, Chen C. Enhancement of the power conversion efficiency for thermoelectric generation. ASME 2013 International Technical Conference and Exhibition on Packaging and Integration of Electronic and Photonic Microsystems 2013.

[15] Rohsenow W M, Hartnett JP, Cho YC. Handbook of Heat and Transfer. 3rd ed. New York: McGraw-Hill; 1998.

[16] Fernando P, Palm B, Ameel T, Lundqvist P, Granryd E. A minichanel aluminum tube heat exchanger- Part I: Evaluation of single-phase heat transfer coefficients by the Wilson plot method. Int J Refrig 2008; 31:669-80.

[17] Yao Y, Huang M, Mo J, Dai S. State-space model for transient behavior of water-to-air surface heat exchanger. Int J Heat Mass Tran 2013; 66(9):173-192. 


\begin{tabular}{|c|c|c|c|c|c|c|c|c|c|c|c|c|c|c|c|c|}
\hline \multicolumn{2}{|c|}{ Working point } & \multicolumn{3}{|c|}{$T_{1}\left({ }^{\circ} \mathrm{C}\right)$} & \multicolumn{3}{|c|}{$T_{2}\left({ }^{\circ} \mathrm{C}\right)$} & \multicolumn{3}{|c|}{$T_{3}\left({ }^{\circ} \mathrm{C}\right)$} & \multicolumn{3}{|c|}{$T_{4}\left({ }^{\circ} \mathrm{C}\right)$} & \multicolumn{3}{|c|}{$T_{C}-T_{a m b}\left({ }^{\circ} C\right)$} \\
\hline Pump & Fan-coil & $\exp$ & $\bmod$ & Error & $\exp$ & $\bmod$ & Error & $\exp$ & $\bmod$ & Error & $\exp$ & $\bmod$ & Error & $\exp$ & $\bmod$ & Error (\%) \\
\hline \multirow{15}{*}{4} & \multirow{3}{*}{5} & 27.3 & \multirow{3}{*}{27.05} & 0.25 & 29.1 & \multirow{3}{*}{28.91} & 0.18 & 29.1 & \multirow{3}{*}{28.90} & 0.19 & 27.2 & \multirow{3}{*}{27.05} & 0.15 & 13.3 & \multirow{3}{*}{13.61} & -2.71 \\
\hline & & 27.3 & & 0.25 & 29.2 & & 0.28 & 29 & & 0.09 & 27.1 & & 0.05 & 14.0 & & 2.79 \\
\hline & & 27.2 & & 0.15 & 29.1 & & 0.18 & 29 & & 0.09 & 27.1 & & 0.05 & 13.9 & & 1.74 \\
\hline & \multirow{3}{*}{4} & 27.7 & \multirow{3}{*}{27.45} & 0.24 & 29.5 & \multirow{3}{*}{29.32} & 0.18 & 29.5 & \multirow{3}{*}{29.30} & 0.19 & 27.6 & \multirow{3}{*}{27.45} & 0.14 & 13.6 & \multirow{3}{*}{14.08} & -3.90 \\
\hline & & 27.5 & & 0.04 & 29.4 & & 0.08 & 29.2 & & -0.11 & 27.4 & & -0.06 & 14.2 & & 0.86 \\
\hline & & 27.6 & & 0.14 & 29.5 & & 0.18 & 29.4 & & 0.09 & 27.5 & & 0.04 & 14.1 & & 0.16 \\
\hline & \multirow{3}{*}{3} & 28.1 & \multirow{3}{*}{27.88} & 0.22 & 30 & \multirow{3}{*}{29.78} & 0.22 & 29.9 & \multirow{3}{*}{29.76} & 0.13 & 28.0 & \multirow{3}{*}{27.88} & 0.11 & 14.8 & \multirow{3}{*}{14.58} & 1.13 \\
\hline & & 28.0 & & 0.12 & 29.9 & & 0.12 & 29.8 & & 0.03 & 27.9 & & 0.01 & 14.8 & & 1.13 \\
\hline & & 28.3 & & 0.42 & 30.2 & & 0.42 & 30.1 & & 0.33 & 28.1 & & 0.21 & 14.9 & & 1.79 \\
\hline & \multirow{3}{*}{2} & 29.0 & \multirow{3}{*}{28.91} & 0.09 & 30.8 & \multirow{3}{*}{30.71} & 0.08 & 30.8 & & 0.10 & 28.9 & & -0.02 & 15.6 & & 2.53 \\
\hline & & 28.9 & & -0.01 & 30.7 & & -0.02 & 30.7 & 30.69 & 0.00 & 28.8 & 28.91 & -0.12 & 15.5 & 15.16 & 1.90 \\
\hline & & 29.3 & & 0.39 & 31.1 & & 0.38 & 31 & & 0.30 & 29.1 & & 0.18 & 15.6 & & 2.84 \\
\hline & & 30.4 & & -0.17 & 32.2 & & -0.20 & 32.2 & & -0.18 & 30.4 & & -0.17 & 16.4 & & -3.54 \\
\hline & 1 & 30.3 & 30.56 & -0.27 & 32.2 & 32.40 & -0.20 & 32 & 32.37 & -0.38 & 30.2 & 30.57 & -0.37 & 17.0 & 16.93 & 0.12 \\
\hline & & 30.8 & & 0.23 & 32.6 & & 0.20 & 32.4 & & 0.02 & 30.6 & & 0.03 & 16.8 & & -0.77 \\
\hline & & 27.1 & & -0.04 & 29.5 & & -0.08 & 29.3 & & -0.26 & 27.0 & & -0.14 & 14.7 & & -0.62 \\
\hline & 5 & 27.1 & 27.14 & -0.04 & 29.5 & 29.57 & -0.08 & 29.3 & 29.55 & -0.26 & 27.0 & 27.14 & -0.14 & 14.6 & 14.79 & -1.31 \\
\hline & & 27.1 & & -0.04 & 29.6 & & 0.02 & 29.4 & & -0.16 & 27.1 & & -0.04 & 14.9 & & 0.73 \\
\hline & & 27.5 & & 0.09 & 29.9 & & 0.09 & 29.7 & & -0.09 & 27.4 & & -0.01 & 15.1 & & 1.20 \\
\hline 3 & 4 & 27.4 & 27.40 & -0.01 & 29.8 & 29.80 & -0.01 & 29.6 & 29.78 & -0.19 & 27.3 & 27.40 & -0.11 & 15.0 & 14.92 & 0.54 \\
\hline & & 27.5 & & 0.09 & 29.9 & & 0.09 & 29.8 & & 0.01 & 27.4 & & -0.01 & 15.0 & & 0.54 \\
\hline & & 28.0 & & 0.21 & 30.4 & & 0.21 & 30.3 & & 0.13 & 27.9 & & 0.11 & 15.6 & & 2.05 \\
\hline & 3 & 27.8 & 27.79 & 0.01 & 30.2 & 30.19 & 0.01 & 30.1 & 30.16 & -0.07 & 27.7 & 27.79 & -0.09 & 15.5 & 15.28 & 1.41 \\
\hline & & 28.1 & & 0.31 & 30.5 & & 0.31 & 30.3 & & 0.13 & 27.9 & & 0.11 & 15.6 & & 2.05 \\
\hline
\end{tabular}




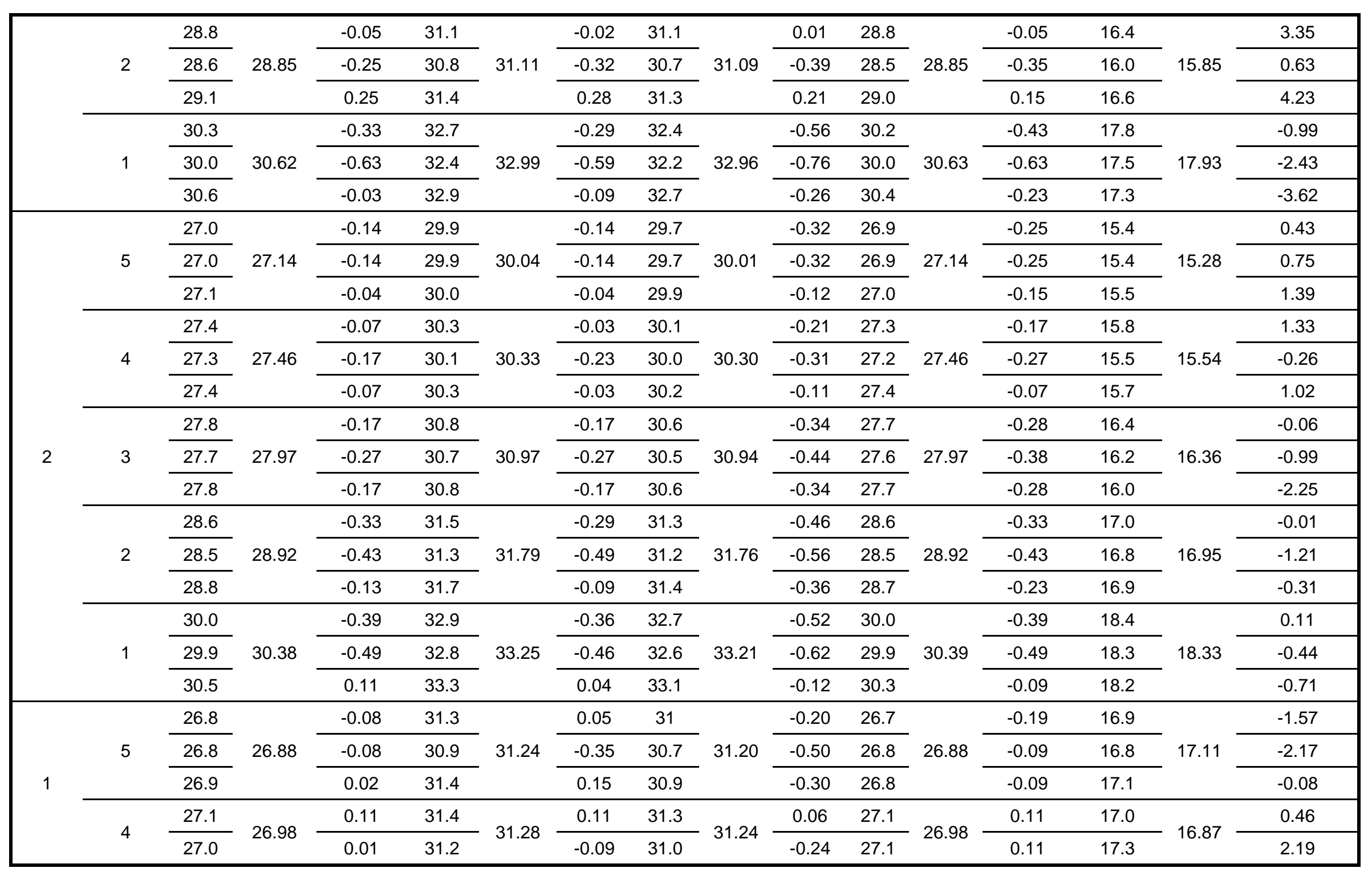




\begin{tabular}{|c|c|c|c|c|c|c|c|c|c|c|c|c|c|c|c|}
\hline & 27.2 & & 0.21 & 31.6 & & 0.31 & 31.2 & & -0.04 & 27.1 & & 0.11 & 17.5 & & 3.58 \\
\hline \multirow{3}{*}{3} & 27.6 & \multirow{3}{*}{27.38} & 0.21 & 32 & \multirow{3}{*}{31.65} & 0.35 & 31.7 & \multirow{3}{*}{31.60} & 0.10 & 27.5 & \multirow{3}{*}{27.38} & 0.11 & 17.8 & \multirow{3}{*}{17.23} & 3.20 \\
\hline & 27.5 & & 0.11 & 31.7 & & 0.05 & 31.5 & & -0.10 & 27.4 & & 0.01 & 17.7 & & 2.38 \\
\hline & 27.8 & & 0.41 & 32 & & 0.35 & 31.7 & & 0.10 & 27.7 & & 0.31 & 18.0 & & 4.27 \\
\hline \multirow{3}{*}{2} & 28.5 & \multirow{3}{*}{28.72} & -0.22 & 32.8 & \multirow{3}{*}{33.02} & -0.22 & 32.5 & \multirow{3}{*}{32.96} & -0.47 & 28.4 & \multirow{3}{*}{28.72} & -0.33 & 18.3 & \multirow{3}{*}{18.58} & -1.83 \\
\hline & 28.3 & & -0.42 & 32.6 & & -0.42 & 32.1 & & -0.87 & 28.2 & & -0.53 & 18.5 & & -0.72 \\
\hline & 28.6 & & -0.12 & 32.9 & & -0.12 & 32.6 & & -0.37 & 28.5 & & -0.23 & 18.9 & & 1.41 \\
\hline \multirow{3}{*}{1} & 29.8 & \multirow{3}{*}{30.12} & -0.33 & 34 & \multirow{3}{*}{34.36} & -0.36 & 33.9 & \multirow{3}{*}{34.29} & -0.40 & 29.9 & \multirow{3}{*}{30.13} & -0.24 & 19.5 & \multirow{3}{*}{19.77} & -1.40 \\
\hline & 29.7 & & -0.43 & 34 & & -0.36 & 33.8 & & -0.50 & 30 & & -0.14 & 19.9 & & 0.38 \\
\hline & 30.2 & & 0.07 & 34.4 & & 0.04 & 33.8 & & -0.50 & 30 & & -0.14 & 20.0 & & 1.13 \\
\hline
\end{tabular}

Table 2: Experimental and computationally simulated values. 